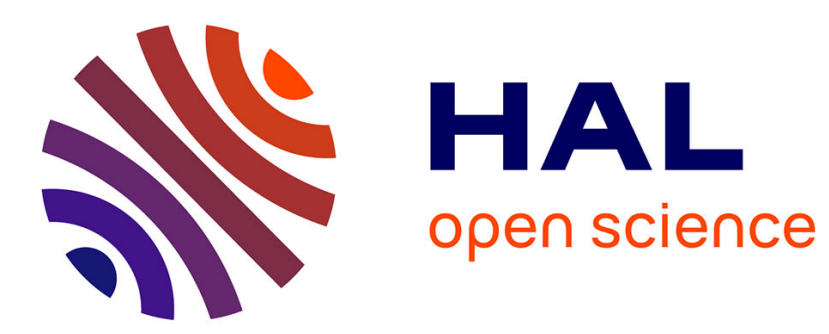

\title{
Flame/Wall interactions: laminar study of unburnt HC formation
}

Marc Chauvy, Bruno Delhom, Julien Reveillon, F.X. Demoulin

\section{To cite this version:}

Marc Chauvy, Bruno Delhom, Julien Reveillon, F.X. Demoulin. Flame/Wall interactions: laminar study of unburnt HC formation. Flow, Turbulence and Combustion, 2010, 84 (3), pp.369. 10.1007/s10494-009-9245-8 . hal-00445505

\section{HAL Id: hal-00445505 https://hal.science/hal-00445505}

Submitted on 8 Jan 2010

HAL is a multi-disciplinary open access archive for the deposit and dissemination of scientific research documents, whether they are published or not. The documents may come from teaching and research institutions in France or abroad, or from public or private research centers.
L'archive ouverte pluridisciplinaire HAL, est destinée au dépôt et à la diffusion de documents scientifiques de niveau recherche, publiés ou non, émanant des établissements d'enseignement et de recherche français ou étrangers, des laboratoires publics ou privés. 


\title{
Flame/Wall interactions : laminar study of unburnt $\mathrm{HC}$ formation
}

\author{
M. Chauvy ${ }^{1,2}$, B. Delhom ${ }^{1}$, J. Reveillon ${ }^{1, *}$, F.X. Demoulin ${ }^{1}$ \\ ${ }^{1}$ CORIA UMR 6614, University of Rouen, France \\ ${ }^{2}$ PSA Peugeot-Citroen, Velizy, France \\ ${ }^{*}$ Corresponding author : Julien.Reveillon@coria.fr
}

January 8, 2010

\begin{abstract}
This work presents a numerical study dedicated to the formation of unburnt hydrocarbon. Two configurations: head-on quenching (HOQ) on a planar wall and in crevices, are considered. It is well known that they contribute for an important part to the sources of hydrocarbon (HC) emission in a combustion chamber. The aim of this work is to use laminar flame simulations (LFS) to understand how the unburnt $\mathrm{HC}$ are produced near walls in gasoline engine. A skeletal mechanism (29 species and 48 reactions) mimicking iso-octane combustion is used. In the HOQ configuration, the flame front propagates toward the cold wall where quenching occurs. The numerical procedure and the chemical scheme used in this study are first validated by comparisons with literature results for the 1D case. Several aspects of flame wall quenching such as oxidation of unburnt HC, wall heat flux, quench distances as well as $\mathrm{HC}$ families are investigated by varying parameters like wall temperature and equivalence ratio. In a second part, crevices are considered to study the impact of wall imperfections in combustion chambers. Configurations with different geometrical and thermodynamic properties are tested. It leads to a wide range of flame properties and $\mathrm{HC}$ production modes. When incomplete combustion occurs, total HC (fuel $+\mathrm{HC}$ ) concentration can reach very high levels at the wall. When the crevice is not wide enough, the flame cannot propagate and the quantity of $\mathrm{HC}$ is smaller than in the case where the flame can propagate (but the fuel is not oxidizing). If the crevice is wide enough for the flame to propagate, HOQ occurs at
\end{abstract}


the bottom of the crevice and $\mathrm{HC}$ accumulate in the corners. The computational results obtained in this work demonstrate the ability of LFS to reproduce incomplete combustion mechanisms that are responsible for a major part of $\mathrm{HC}$ production in gasoline engines.

\section{Introduction}

Legislation on hydrocarbons (HC) emissions in gasoline engine is more and more drastic. Moreover, new injection and combustion strategies are studied to increase the efficiency and to reduce pollutants like Nitrogen Oxides. Examples are provided by direct injection, exhaust gas recirculation or homogeneous charge compression ignition. Unfortunately, these new strategies tend to increase the unburnt $\mathrm{HC}$ emission levels. As a consequence, the need to model the $\mathrm{HC}$ formation becomes primordial.

A comprehensive account of the HC sources and the mechanisms leading to their formation and oxidation is summarized by Heywood [26] and Cheng [13]. The main sources are : crevices in combustion chamber, absorption and desorption by oil film, deposits in combustion chamber, flame quenching, mixture and incomplete combustion and intake / exhaust valve leakage. A classification of $\mathrm{HC}$ sources by mass of HC [13] reveals that combustion chamber crevices produce $38 \%$ of the total HC. The basic flame / wall quenching is accountable for only $5 \%$ of the total mass of HC. However, under cold-start conditions, the amount of $\mathrm{HC}$ emission coming from basic flame / wall quenching is equivalent to the one from combustion chamber crevices. Therefore, in the present work, we focus on these two sources of HC (flame quenching and crevices).

Many authors have done experiments to demonstrate and quantify the HC emissions due to crevices $[22,2,46]$. Others authors have studied the influence of the dimensions of the ring orifice system and the dimensions of the crevice size $[37,1]$. Boram et al. [6] observed a diminution of $\mathrm{HC}$ emission with a reduction in the piston top-land crevice. Finally, measurements showed that the mass of HC issued from the crevice region is proportional to the crevice volume [3], which depends on the temperature and thermal dilatation of the piston and cylinder liner. Even if crevices are the most important sources of HC, only few numerical studies exist on this topic. In most these articles, the authors work with configuration of tube quenching in the case of laminar [29] and turbulent flows [10]. The flame propagates through an open tube and quenching occurs at the bottom wall of the tube. If the diameter of the tube is too small, the flame cannot propagate.

Quenching was first observed by Daniel [15]. He studied a flame near a cold wall in a spark ignition engine and observed a quenching layer. Many studies (theoretical, 
numerical and experimental [41]) that have been dedicated to flame quenching used a simple configuration: a flame propagates perpendicular to a cold wall and HOQ occurs. In this configuration (laminar one-dimensional), the flame / wall interaction is first controlled by the wall thermal effects, and then by chemistry [9, 44]. Generally, authors seeks to quantify the influence of the flame / wall interaction on the heat transfer and the pollutant formation $[4,5,19,35,36,34]$. The chemical process occurring near the walls of combustion chambers control some essential aspects of an engine's performances. The high heat fluxes and the formation of unburnt HC, for example, are often due to flames interacting with walls [40]. In engines, laminar models offer a good agreement for quench distances [21, 20, 32]. Because thermal wall effects first control the flame, many authors [11, 27] used a simple chemistry. Other works $[47,43]$ compare simple and complex chemistry. They reach similar conclusions: the size of the chemical mechanism does not change the wall heat flux and quench distances. On another hand, Westbrook [47] works with low molecular weight fuels (methanol and methane). These fuels have limited pathways of forming $\mathrm{HC}$ during the combustion. Concerning fuels with more important molecular weight, which have more HC pathways formations, it has been shown [24, 31] that the quantity of total $\mathrm{HC}$ exceed the quantity of pure fuel. Consequently, it is preferable to use a complex chemistry that takes into account several pathways of forming $\mathrm{HC}$ and interactions between transport and oxidation in the gas.

The aim of this work is to study the production and evolution of unburnt $\mathrm{HC}$ in the vicinity of walls. This production of $\mathrm{HC}$ is determined thanks to a direct numerical simulation code used in the case of laminar flame wall interactions. It is a great tool to investigate the reacting flow processes that control pollutant production, transport and combustion. Two configurations are studied: a 1D case scrutinizes the quenching of laminar, premixed flames interacting with a cold wall, while the second case is a $2 \mathrm{D}$ crevice configuration where flame propagates. Walls are considered dry in this work. These configurations are not completely representative of a realistic combustion chamber where there is wall motion and a more complex geometry. However, it allows us to focus on the specific issue of the impact of wall heat transfers on the unburnt $\mathrm{HC}$ evolution. The use of a complex kinetic scheme make sure that the model describes with accuracy the chemical effects during the quenching. The fuel that has been selected in this study is iso-octane, which is widely used as a reference fuel for gasoline engine.

In the first part of this paper, the numerical approach used to address the problem of $\mathrm{HC}$ formation during flame quenching is detailed. Equations to be resolved are shortly described together with the corresponding numerical procedure used to solve them. Then, chemical schemes of various complexity are considered to find an 
optimum balance between accuracy and computational cost. Finally the retained approach is validated thanks to a previous study dedicated to HOQ, and first results about $\mathrm{HC}$ formation are presented. In the second part of the paper the approach is applied to the case of a flame reaching a crevice. First, numerical considerations are addressed because of the important computational cost of $2 \mathrm{D}$ simulations when complex chemistry is applied. Main results are then presented with respect to the wall temperature and crevice thickness before an analysis of the $\mathrm{HC}$ formed during the combustion in such geometry.

\section{Computation of $\mathrm{HC}$, numerical considerations}

\subsection{Numerical Model}

Direct numerical simulation is a powerful way to study laminar and turbulent flows. Indeed, Navier-Stokes (NS) equations are resolved with highly accurate and nondissipative numerical methods that are able to capture all the characteristic time and space scales of the considered flow. No model are necessary to observe the development and the evolution of turbulent structures and all results may be considered to be as close as possible from reality. Occasionally, such accurate numerical simulation is even denoted as a 'numerical experiment'. However the grid mesh has to be fine enough to capture the smallest scales of the flow and therefore, the computational cost may be skyrocketing.

Many formulations may be derived for the NS equations. The fully compressible equations allow for a complete description of the physics including acoustic phenomena. Apart from having a very small time step mainly based on the sound velocity, the main difficulties lie in a good formulation of the initial and boundary conditions that must account for entering and exiting acoustic waves. If acoustic phenomena are neglected, it is possible to select a low mach number (LMN) formulation with either a constant or variable density flow. Then, boundary conditions are straightforward to prescribe. However, an elliptic solver is needed to resolve the momentum balance equation and a splitting procedure has to be used to determine chemical source terms. For non-reactive flows, the computational cost may be reduced by a factor of 5 to 10 compared to the corresponding compressible formulation.

NS equations are normalized by reference physical quantities denoted with a 0 subscript. Among them, the reference velocity is defined by

$$
u_{0}=M \sqrt{\gamma r_{0} T_{0}}
$$

where $M$ denotes a reference Mach number, $\gamma$ the specific heat ratio, $r_{0}$ the universal 
gas constant divided by the molar mass of a reference mixture and $T_{0}$ the temperature. The following usual dimensionless numbers have been introduced to simplify the expressions :

$$
R e=\frac{\rho_{0} u_{0} x_{0}}{\mu_{0}}, \quad S c_{k}=\frac{\mu}{\rho D_{k}}, \quad \operatorname{Pr}=\frac{C_{p} \mu}{\lambda}
$$

which are the Reynolds, Schmidt and Prandtl numbers, respectively.

The basic principle of the LMN formulation is to define $\epsilon=\gamma M^{2}$ with $\epsilon<<1$ and to decompose any physical data $A$ into series $A=A^{(0)}+\epsilon A^{(1)}+\epsilon^{2} \ldots$. Because of the LMN hypothesis, only the 0 order terms are conserved except in the momentum equation where the first order terms are also considered. In the following, to simplifying notations, $A^{(0)}=A$.

The LMN form of the NS equations describing the evolution of the density $\rho$ (Eq. 2), the $k$-th species mass fraction (Eq. 3), the sensible enthalpy $h_{s}$ (Eq. 4) and the momentum $\rho u_{i}$ (Eq. 5) may be written:

$$
\begin{gathered}
\frac{\partial \rho}{\partial t}+\frac{\partial \rho u_{i}}{\partial x_{i}}=0 \\
\frac{\partial \rho Y_{k}}{\partial t}+\frac{\partial \rho\left(u_{i}+V_{i}^{c}\right) Y_{k}}{\partial x_{i}}=\frac{\partial}{\partial x_{i}}\left(\rho D_{k}^{\bullet} \frac{\partial Y_{k}}{\partial x_{i}}\right)+\dot{w}_{k} \\
\frac{\partial \rho h_{s}}{\partial t}+\frac{\partial \rho u_{i} h_{s}}{\partial x_{i}}=\frac{\partial}{\partial x_{i}}\left(\lambda \cdot \frac{\partial T}{\partial x_{i}}-\rho \sum_{k=1}^{N} h_{s, k} D_{k}^{\bullet} \frac{\partial Y}{\partial x_{i}}\right)+\dot{w}_{T} \\
\frac{\partial \rho u_{j}}{\partial t}+\frac{\partial \rho u_{i} u_{j}}{\partial x_{i}}=-\frac{\partial p^{(1)}}{\partial x_{j}}+\frac{\partial \tau_{i j}}{\partial x_{i}}
\end{gathered}
$$

together with the equation of state for perfect gases:

$$
p^{(0)}=\rho r T
$$

In order to conserve a usual appearance of these transport equations, the following conductivity, diffusion and viscosity have been defined from the normalized quantities:

$$
\lambda^{\bullet}=\frac{C_{p}^{+} \mu^{+}}{\operatorname{RePr}}, \quad D_{k}^{\bullet}=\frac{\mu^{+}}{\rho^{+} \operatorname{ReSc_{k}}}, \quad \mu^{\bullet}=\frac{\mu^{+}}{R e}
$$

The stress tensor is defined by

$$
\tau_{i j}=\mu^{\bullet}\left(\frac{\partial u_{i}}{\partial x_{j}}+\frac{\partial u_{j}}{\partial x_{i}}\right)-\frac{2}{3} \mu^{\bullet} \frac{\partial u_{l}}{\partial x_{l}} \delta_{i j}
$$


while a correction term is introduced to ensure that species diffusion leads to a null global mass flux [41]:

$$
V_{i}^{c}=\sum_{k=1}^{N} D_{k}^{\bullet} \frac{\partial Y_{k}}{\partial x_{i}}
$$

The pressure $p^{(1)}$, in equation (5), represents the dynamic pressure associated to the flow and does not participate in the thermodynamic process. An elliptic solver is necessary to determine its value.

The reaction rate $\dot{w}_{k}$ is the net chemical production rate of species $\mathrm{k}$. It is calculated thanks to a coupling with Chemkin [30] and the DVODE solver [8]. $\dot{w}_{T}$ is the heat release due to combustion,

$$
\dot{w}_{T}=-\sum_{k=1}^{N} \Delta h_{f, k}^{0} \dot{w}_{k}
$$

where $\Delta h_{f, k}^{0}$ corresponds to the formation enthalpies.

To solve the gas phase transport equations on a regular mesh, the sixth order PADE scheme from Lele [33] has been used to determine spatial derivatives. The time integration of gas phase equations is done with a third order explicit RungeKutta scheme with a minimal data storage method [48].

Popp et al. [45] have made a summary of the various possibility concerning the boundary conditions: inert wall/no cross diffusion, inert wall/cross diffusion and reacting wall. The cross diffusion is also called the Soret and Dufour mass and heat diffusion. Here, the first kind of boundary condition is applied to study the interaction of the flame with a moderately hot wall at atmospheric pressure. This approach is useful for theoretical studies of flame quenching [19] with application to engine. It consists in fixing a null velocity and fresh gases temperature at the wall location. $T_{w}$ is kept constant during the simulation in accordance with experimental evidences [18]. In addition, a null gradient boundary condition is applied for the species at the wall. In these conditions, the Soret effect is not taken into account. Recently Hasse et al. [30] have studied the relative importance of Soret and Dufour effects for 1D HOQ configuration. At a pressure of 10 bar it was found that the Sorret effect should be considered otherwise the oxidation of hydrocarbons could be overpredicted. Concerning the Dufour effects, Hasse et all. [30] indicate that it does not influence the results significantly for wall temperatures up to $600 \mathrm{~K}$. The main goal of the present study is to extend HOQ simulations to more complex geometry thank to 2D simulations. It appears that it is possible to neglect the Dufour effect in our simulation because the maximum wall temperature considered will be $500 \mathrm{~K}$. 
The Soret effect could be more important in particular to extend the present work to higher pressure. Adding Dufour and Soret effect to understand their influences on flame quenching in complex geometry must be the subject of further work to approach real engine conditions.

\subsection{Chemical Kinetics}

A chemical mechanism for the oxidation of iso-octane is applied in this study. It has been described in [24]. It is based on the Peters mechanism composed of 56 species and 189 reactions. It has been validated with the results of Bradley [7]. However, detailed kinetics are computationally expensive. To diminish the computational cost, Hasse has developed a reduced kinetic scheme based on Peters [39]. He selected major reaction paths and species and he added three species, eight reactions and eight another reactions to be reversible. The construction of this new mechanism allowed to conserve the flame structure while the quenching model is always in good agreement with the detailed mechanism. This mechanism contains finally 29 species and 48 reactions. Hasse's mechanism is referred as "Hasse" in the following text and is applied in all LFS configurations.

An additional mechanism denoted "Golovitchev" is used in this part. It is a comprehensive mechanism and it consists of 121 species and 611 reactions [38]. This mechanism was constructed for gasoline surrogates. It is sufficiently detailed and general to be valid for a wide-range of engine operating conditions, while keeping the mechanism as small as possible. It has been validated with the kinetics mechanisms of Curran [14]. This last mechanism is considered as a reference because it has been developed to represent iso-octane combustion in engine conditions. The dimension of Golovitchev mechanism is too important for practical LFS applications. Thus it is only used to verify that Hasse's kinetics allows for a good estimation of unburnt HC.

In figure 1, comparisons between the two mechanisms have been carried out. The configuration is a 1D freely propagating laminar flame. Initial conditions are the following: equivalence ratio is equal to 1, temperature of fresh gases is $400 \mathrm{~K}$ and pressure is equal to 1 bar. Temperature and HC (without fuel) are plotted. Hasse's mechanism gives a temperature gradient larger than Golovitchev's and it had a lower burnt gas temperature: $2284 K$ (Golovitchev) and $2148 K$ (Hasse). HC profiles are similar for both mechanisms and they increases slightly ahead of the corresponding temperatures profiles. We note that residual concentration levels of $\mathrm{HC}$ behind the flame are negligible or very small in both cases : $Y_{H C}=6.110^{-7}$ (Golovitchev) and $Y_{H C}=2.510^{-3}$ (Hasse). This study demonstrates that evolutions of temperature 
and $\mathrm{HC}$ are globally similar with both chemical schemes, even if slight discrepancies exist.

Because of the reduced dimension of Hasse's mechanism, it is not possible to compare all detailed species. It is more pertinent to classify the $\mathrm{HC}$ species in families (Tab. 1): Paraffin, Olefin, Naphthalene, Acetylenic, Oxygenate and "others" (that corresponds to radical species) [23]. For families like Paraffin, Olefin and "Others", we have similar evolution and concentration with both mechanisms (Fig. 2). For acetylenic and oxygenate families, the maximum levels of mass fraction is different. Finally, Hasse's mechanisms does no contains naphthalene.

This comparison shows the limits of Hasse's mechanism. Some information is missing since data are available only about some families and not about each species as offered by Golovitchev mechanism. Nevertheless Hasse's mechanism gives correct information on the evolution of the temperature, the $\mathrm{HC}$ concentration and the major HC families (paraffin, olefin and radical species). Even if the flame wall interaction is first controlled by thermal effect [41], the use of Hasse's mechanism will be useful to get a deeper comprehension of the complex chemical processes involved in the HC production.

\section{$2.3 \quad$ Head-On Quenching}

A one-dimensional laminar flame propagates into fresh reactants towards a wall that will remain at the fresh gases temperature. In this case, the grid resolution in the computational domain is a critical issue to achieve grid independency of the results for a flame wall interaction. The needed resolution is higher than for a freely propagating flame to capture accurately physical and chemical phenomenon near the wall. Moreover the flame is unsteady. Previous studies $[43,24,16]$ have grid spacing of the order of micrometers. In addition, a length of $1 \mathrm{~cm}$ for the computational domain is enough to ensure that the influence of the open boundary on the quenching process is negligible [24].

To initialize the LFS calculations, a freely propagating flame (with desired initial conditions like fresh gas temperature or initial concentrations of different species) is calculated. The flame is placed adequately in the computational domain to avoid any initial influence from the wall or the output conditions. It has been checked that the flame propagates at a constant velocity for some time before the wall affects its properties.

Flame/wall distance is usually normalized by the laminar flame thickness. From 
a normalized point of view, it corresponds to a Peclet number of quenching progress:

$$
P e=\frac{x_{w}}{\delta_{f}}
$$

where $x_{w}$ is the distance between the flame and the wall. The flame is localized at the temperature level $1500 K[47,31]$ and its thickness is defined by [24]:

$$
\delta_{f}=\frac{\Delta T}{\left(\frac{\partial T}{\partial x}\right)_{\max }}
$$

where $\Delta T=T_{b}-T_{u}$ where $T_{b}$ is the burnt gases temperature. Since the diffusion and the convective velocities are null at the wall $[41,43]$, the heat flux is defined by

$$
q_{w}=\lambda_{w}\left(\frac{\partial T}{\partial x}\right)_{w}
$$

where the conduction coefficient $\lambda_{w}$ depends on the surface temperature and mixture concentration at the wall and the temperature gradient is given by the LFS calculation. Note that this formulation does not consider any radiative heat transfer between the hot gases and the flame, which is in accordance with previous works [40, 28, 18]. The heat flux $q_{w}$ is usually scaled by the laminar reference "flame power",

$$
\Phi_{w}=\frac{q_{w}}{\rho C_{p} S_{l} \Delta T}
$$

where $S_{l}$ is the freely evolving laminar flame velocity. In the following, distances are normalized by the laminar flame thickness, $x^{*}=x / \delta_{f}$ and times are normalized by $t_{f}=\delta_{f} / S_{l}$. The non-dimensional time $t^{*}=t / t_{f}$ origin has been fixed at the quenching moment. Therefore, when $t^{*}<0$, the flame propagates towards the wall and when $t^{*}=0$, the quenching occurs.

Figure 3 shows the time evolution of the temperature profile. Initialy, the flame propagates without modification (before $t^{*}=-0.54$ ) from right to left. Near the wall, the flame front is affected $\left(t^{*}=-0.27\right)$ and the temperature gradients increase. After a while, the flame stops and quenching occurs $\left(t^{*}=0\right)$. It is characterized by a minimal distance between the flame and the wall. At this location the strongest temperature gradient may be observed. This gradient is at the origin of an important wall heat flux that leads to a decay of the temperature $\left(t^{*}>0\right)$. Heat diffusion process dominates this last step. These results are similar to descriptions made by $[41,24,16]$.

To characterize the HOQ, it is generally accepted to use two parameters: the Peclet number and the wall heat flux whose evolutions are shown in figure 4 . The 
Peclet number decreases down to the value $P e=0.38$, which is the quenching distance. Parallely, the wall heat flux increases until it reaches a maximum at the same time $t^{*}=0$. In table 2 Peclet numbers and wall heat fluxes are compared to Hasse's results [24] for various wall temperatures. Peclet numbers are almost similar for both computations and wall heat fluxes are very close. This good agreement asseses the ability of the present approach to deal with flame quenching at the wall and to capture HC formation. The slight differences between the two simulations may be explained by the fact that Soret and Dufour effects are neglected in our work.

The time evolution of the fuel mass fraction profile is plotted in figure 5-(a). The concentration of fuel decreases when the flame goes toward the wall $(t *<0)$ and, eventually is fully consumed $(t *>0)$. On contrary when a single step chemistry is used, a small amount of fuel remains at the end of simulation [16]. With the more detailed chemistry used in our work, HC are still present after quenching (Fig. 5-(b)). Then, the $\mathrm{HC}$ mass fraction becomes more important than the fuel mass fraction. These results are in agreement with [47, 43].

The formation of HC can be divided in two steps $[12,17]$ : first the fuel is oxidized into $\mathrm{HC}$ species that can be classified in various families, second, $\mathrm{HC}$ are oxidized into $\mathrm{CO} / \mathrm{CO} 2$. In figure 6 , the percentage of each family is shown at four normalized time $\left(t^{*}=-1,-0.2,0\right.$ and 0.2$)$. Let's recall that time $t^{*}=0$ is the quenching instant of the considered computation. In the case of Hasse's mechanism, the paraffin family is only composed of iso-octane. In table 3 , the total mass fraction of unburnt $\mathrm{HC}$ in the domain is summarized for each case and time.

When $t^{*}=-1$, all cases are composed of just about the same proportion of families: paraffin, olefin, others species, acetylenic and oxygenate. At the following instant $t^{*}=-0.2$, differences between $\phi=0.8$ and $\phi=1.0$ are very small. The proportion of paraffin and olefin decreases whereas "others" and acetylenic increase. When $\phi=1.4$, the difference with $\phi=1$ is more important: paraffin and acetylenic levels increase whereas olefin and "others" decrease. If the wall temperature increases, the concentration of paraffin decreases whereas all the others families increase their proportions. When quenching occurs $\left(t^{*}=0\right)$, same kind of behaviours than $t^{*}=-0.2$ may be observed. Finally, after the quenching, when $t^{*}=0.2$ and the equivalence ratio is lower or equal than 1 , the fuel consumption is over. The proportions of each family for these two equivalence ratios are very close. When $\phi$ is greater than 1, there is still some paraffin remaining. Fuel could not be converted into others families in totality because paraffin is present in too large quantity. If $T_{w}=300 \mathrm{~K}$, traces of fuel are present and when $T_{w}$ increase, olefin decreases whereas acetylenic family increases. After, $t^{*}=0.2$, the major proportions of each family are conserved in all subcases shown. Figure 6 shows that after the quenching the composition of 
$\mathrm{HC}$ is composed by about $1 / 3$ of olefin, $1 / 3$ of acetylenic and $1 / 3$ of "others". Only for the case where equivalence ratio is equal to 1.4, there exist few radicals families. In some case (cold wall or equivalence ratio greater than 1) some fuel remains in the composition. At the wall, oxygenate appears in very low quantities.

In engines applications, after HOQ, a post diffusion quenching occurs with fresh gases along the wall. In fact, characteristic time of the flame for HOQ are smaller than characteristic time of engine. Thus HOQ cannot be an important $\mathrm{HC}$ source for normal operating engine condition although in the case of cold start engine, HOQ produces important $\mathrm{HC}$ quantities [25]. Many authors agree to the fact that the main source of $\mathrm{HC}$ in engine are the crevices. In the following, we will focus on the crevices after some computational considerations.

\section{$3 \quad$ Flame in crevice}

This part presents the simulation of flames propagating in crevices, which are represented by a rectangular tube quenching that is closed at one extremity.

\subsection{Computational Considerations}

To reduce the computational time of reacting flows with more complex configurations than 1D HOQ, an "in situ" adaptive tabulation (ISAT) [42] has been used. The principle of this method is to store the reacting map corresponding to the composition (temperature, species) of each calculation point in a binary tree. If the composition of a given point has never been evaluated a regular full chemistry evolution is carried out and then stored in the tree. This composition will not be calculated twice if it appears again during the computation. On the other hand, if the composition point is close to one that was evaluated in the tree, a linear estimation is carried out between the data of the tree. The solver accuracy and efficiency are directly (and in opposed way) linked to the tolerance value that is adopted for the computations. In conclusion, the tree grows with each iteration while the computational cost diminishes. This kind of approach is much faster than classic chemistry but it has a drawback: it requires an important memory capacity to store the tree when the chemical mechanism is large.

Another way to reduce the computational time is to replace the strong coupling, which corresponds to a an estimation of the chemical source terms for all sub-steps of the third order Runge-Kutta procedure by a weak coupling where only one estimation of the source terms is carried out. All these simplifications allow to have a reasonable computational time with little loss of information. Five different procedures are evaluated in table 4 . 
The first procedure is the global chemistry (Fuel + Oxidant $\Rightarrow$ Product), which represents the fastest way to operate. It is generally able to capture the global properties of a flame: velocity, thickness, heat-release. But it does not capture its inner structure of the flame or the intermediate species. It is thus in complete opposition with the objectives of this paper. The second procedure in table 4 involves a complex chemistry resolution with a strong coupling. The highest accuracy is obtained but the computational cost is problematic. It can not be used with large mechanisms like the one of Golovitchev. To reduce the computational cost, it is possible to use a weak coupling with the chemistry as in the third procedure. The accuracy is then slightly depreciated. However, it is necessary to associate the ISAT procedure and the weak coupling to obtain a reasonable computational cost while maintaining a good accuracy of the chemistry evolution.

Consequently, the detailed kinetics of Hasse has been used in the following of this work along with the ISAT methodology associated with a weak coupling for the chemical source terms.

\subsection{Configuration}

The crevice is represented by a rectangular tube closed at one extremity (Fig. 7). In actual engine, once the flame pass through the entrance of a crevice, the surrounding gas composition remains the same. It corresponds to hot burnt gases. To mimic this effect the ignition spot used to initialize the flame is sustained during the computation. The left side of the geometry, corresponding to $x^{*}=0$, is open and an isothermal wall is surrounding the three other sides. The tube is $7.5 \delta_{f}$ long, where $\delta_{f}$ is the reference laminar flame thickness. This basic configuration is laminar and a symmetry axis is defined to carry out computations on half of the domain.

To initialize the computation, a premixed flame spot is introduced at the inlet of the domain (Fig. 7). The initial flame profile has been obtained from 1D computations. All simulations are conducted for a unitary equivalence ratio. Three fresh gases temperature, which are equal to the walls temperature, are considered: $T_{w}=300 \mathrm{~K}, T_{w}=400 \mathrm{~K}$ and $T_{w}=500 \mathrm{~K}$. The pressure remains equal to 1 bar.

Various geometrical parameters have been tested as well, leading to a wide range of combustion regimes. These parameters lead to various unburnt HC production modes from a geometrical point of view : in the core of the quenched flame, along the walls parallel and perpendicular to the direction of propagation or in the crevice corners. The crevice length and thickness are denoted $L^{*}$ and $y^{*}$, respectively. $L^{*}$ is constant for the various sub-cases $\left(L^{*}=L / \delta_{f}=7.5\right)$ while $y^{*}$ takes the three following values: $y *=y / \delta_{f}=3,4$ and 5 . Note that in this $2 \mathrm{D}$ configuration, $t^{*}=0$ 
corresponds to the beginning of the simulation.

\subsection{Temperature and Crevice thickness}

As expected, it may be observed in figure 8 that the effects of the crevice lateral walls are more and more prevalent as $y^{*}$ decreases. Indeed, for the presented cases with a wall temperature equal to $400 \mathrm{~K}$, the flame is able to propagate in the tube down to the bottom wall as soon as the crevice thickness is large enough $\left(y^{*}=5\right)$.

Along the central axis, the quenching distance of the flame corresponds to the one obtained with the HOQ simulation. However, as soon as the crevice thickness diminishes, the thermal effects affect the flame propagation and it may be seen that in case $y^{*}=4$, the quenching distance is much larger than in case $y^{*}=5$ while in case $y^{*}=3$ the flame is not able to propagate in the domain. It appears that among the nine configurations that have been scrutinized $\left(T_{w}=300 \mathrm{~K}, 400 \mathrm{~K}, 500 \mathrm{~K}\right.$ and $y *=3,4$ and 5 ), five flames are able to propagate inside the crevice while the other four stay at the inlet. The flames propagate for any crevice thickness when the wall temperature is equal to $T_{w}=500 \mathrm{~K}$. On the other hand, the flame is not able to penetrate the crevice if the temperature is too low $\left(T_{w}=300 \mathrm{~K}\right)$ whatever the crevice thickness. An intermediate case $\left(T_{w}=400 \mathrm{~K}\right)$ has thus been introduced to capture the transition between propagation $\left(y^{*}=4\right.$ and 5$)$ and non-propagation $\left(y^{*}=3\right)$ of the flame.

Typical velocity modulus and velocity vectors have been plotted in figure 9 when $T_{w}=400 K$ and $y^{*}=4$. Four various times are shown. At first, the atmosphere is quiescent. Then, velocity vectors appear in both the fresh and burnt gases when the flame begins to propagate. The burnt gases are straightly evacuated outside the crevice while the fresh ones are trapped in the bottom of the crevice and bypass the flame along the lateral wall. The time evolution of the velocity of the five propagating flames is shown figure 10. The flame velocities $S_{c}$ in the crevice are normalized by the speed $S_{l}$ of the reference freely evolving laminar flame propagating in $400 \mathrm{~K}$ fresh gases: $S_{c}^{*}=S_{c} / S_{l}\left(T_{u}=400 \mathrm{~K}\right)$.

The evolution of flame speed in the crevice may be divided in three stages : first an acceleration process due to the initialization of the configuration. Then the flame velocity reaches a stationary value while the flame is far from the bottom wall. Finally the flame reaches its quenching position and its velocity decreases suddenly to zero.

The second stage, (Fig. 10) shows that when the crevice temperature corresponds to the reference flame fresh gases temperature $\left(T_{u}=400 K\right)$, the normalized flame speed remains smaller than unity. Indeed, when $y^{*}=4, S_{c}^{*}=0.6$ and when $y^{*}=5$, 
then $S_{c}^{*}=0.8$. Thus, crevice geometry, through the transverse wall heat flux plays an important role on the flame properties even during propagation phase. When the crevice temperature increases $(T=500 K)$, the flame speed increases because of the growth of the reaction rate. Normalized velocity is larger than unity may be observed : when $y^{*}=4, S_{c}^{*}=1.2$ and when $y^{*}=5$ then $S_{c}^{*}=1.4$. Thus, for a constant crevice width, if $T_{w}$ increases of $100 \mathrm{~K}$, the corresponding flame speed is almost doubled. The temperature is naturally a prevalent parameter concerning the flame propagation but the impact of the wall heat transfers multiply the temperature influence. Indeed, if a freely propagating flame is considered, increasing the fresh gases temperature from $400 K$ to $500 K$ leads to a flame velocity ratio of 1.4 whereas the same temperature increment in the crevice implies a ratio of 1.8 .

The third stage of the flame velocity evolution corresponds to the HOQ with the bottom wall. When the crevice is large $\left(y^{*}=5\right)$ lateral thermal effects remains weak and the Peclet number is very close (for example when $T_{w}: 400, P e=0.35$ ) to the one determined in the HOQ of this paper (fig. 4 -(a)). When $y^{*}=4$, the flame has much more difficulties to progress toward the bottom wall and the quenching distance increases $P e=0.40$. Concerning the thickness $y^{*}=3$, the wall thermal effects are so important that the flame is never able to progress in the tube.

It is also possible to define a minimum transverse Peclet number plotted in figure 11. It corresponds to the normalized minimum quenching distance $\left(P e_{t}\right)$ of the flame part that propagates along the lateral walls. As for the Peclet number defined in equation 8 , the position of the flame is detected by the location of the temperature level $1500 \mathrm{~K}$. Figure 11 represents the evolution of the minimal $P e_{t}$. The three stages of the flame propagation can be retrieved through the temporal evolution of $P e_{t}$. First, during the flame initialization, $P e_{t}$ decreases as the flame progresses toward the wall. Then, a nearly constant $P e_{t}$ number is observed during the propagation of the flame toward the bottom of the crevice. Finally, the flame is quenched and $P e_{t}$ increases because iso-temperature $1500 \mathrm{~K}$ recedes from the wall. During the second step, the flame shape and velocity (Fig. 10) are nearly constant. A remarkable fact is that the transverse Peclet number, which can be observed during the propagation, is equivalent to the one found in the 1D HOQ configuration (Table 2).

\subsection{Comparison of $\mathrm{HC}$ production and fuel destruction}

In figure 12, the time evolution of the fuel and $\mathrm{HC}$ mass fractions in the $2 \mathrm{D}$ domain are represented in the case of a wall/fresh gases temperature equal to $400 \mathrm{~K}$. In the top half of each domain, HC mass fraction (without fuel) is plotted. The fuel mass fraction is represented in the bottom of each domain. When $y^{*}=3$, the fuel is slowly 
oxidizing into $\mathrm{HC}$ and the flame is quickly stopped when $t^{*}=3.64$. It is observed that even if the flame does not propagate anymore, its thickness increases when compared to freely propagating flames. The total quantity of fuel in the crevice continue to diminish but at a smaller rate. To understand the structure of this stabilized or still flame, the evolution of the temperature profiles along the main axis is represented for a propagating flame (Fig. 13-(a)) and for a still flame (Fig. 13-(b)). For both cases the initial temperature profile is similar (first profile from the left hand side of each figure). The inlet flame profile induces a high temperature gradient at the entrance of the crevice. It promotes heat transfer toward the fresh gases inside the crevice. In propagating flame case (Fig. 13-(a)), fresh gases reach ignition temperature and the flame propagates. Concerning the still flame, thermodynamic conditions allowing a flame to propagate are never reached because of the heat losses through the walls. Nevertheless, extinction does not occur since the high gas temperature at the entrance is sustained along the computation to mimic the fact that outside of the crevice the atmosphere is full of hot burnt gases. The stabilisation of these flames is thus related to the parameters used in these simulations. In this work, it is assumed that the external gases temperature remains constant. This assumption has been used because the energy dissipated in the crevice is negligible when compared with the total energy contained in the combustion room for an actual engine. Additionally it can be expected that the rate of heat transfer to the crevice by laminar conduction is negligible when compared to the turbulent mixing that occurs outside of the crevice. Though such an assumption has to be proved, the required numerical simulation to study it would consist of a turbulent combustion room together with a small crevice. This kind of simulations is not available yet.

When $y^{*}=4$ and until $t^{*}=3.64$, conversion of fuel into HC is similar to the case $y^{*}=3$ even if the flame is faster than in the first case. After $t^{*}=3.64$, the HC are concentrated in large quantities at the wall in the wake of the flame front. When $y^{*}=5$, along the axis, the evolution of the data is similar to the one obtained with HOQ presented in the first part of this paper.

In figure 14 we present $Y_{H C}$ and $Y_{\text {fuel }}$ fields at the characteristic time $t^{*}=8.73$ and for two crevice temperatures $(300 K$ on the left of the figure and $500 K$ on the right). For a wall temperature equals to $300 K$, all flames become unable to propagate into the crvice and become still flames similar to the case $T_{w}=400 \mathrm{~K}$, $y^{*}=3$. On the contrary, when $T_{w}=500 \mathrm{~K}$, all flames are able to propagate similarly to the case $T_{w}=400 K, y^{*}=5$.

Thus, figure 14 presents the two possible evolutions of the combustion process in a crevice : either the flame is not able to reach the bottom wall (left) and the reaction of $\mathrm{HC}$ is based on a slow diffusion process located at the crevice entrance. 
Either the flame is able to propagate (right). In this latter case a $\mathrm{HC}$ wake may first be observed along the lateral walls behind the flame front. The edges of the flame are thicker than a freely propagating flame and a noticeable amount of $\mathrm{HC}$ is present inside the flame front. Nevertheless, behind the flame, the amount of $\mathrm{HC}$ is small and equivalent to what is found behind a freely propagating flame. Then, the flame reaches the bottom wall and extinguish. The remaining $\mathrm{HC}$ are located in the corner of the crevice where the heat transfers are intense and prevent any propagation of the flame, whatever the size of the crevice. The remaining $\mathrm{HC}$ oxidation occurs through a slow diffusion process.

Since an actual engine includes many sort of crevice geometries, the total amount of remaining $\mathrm{HC}$ induced by flame/wall interactions directly depends on three characteristics delays : the delay necessary to reach the bottom wall of the crevice, the delay to oxidate the $\mathrm{HC}$ formed in the tails of the flame along the lateral walls and finally, the delay to diffuse and oxidate the $\mathrm{HC}$ trapped in the crevice corners.

The possible two combustion modes that exist in crevices are summarized in table 5. The first regime consists in a flame able to propagate inside the crevice until a HOQ occurs with the bottom wall. While it propagates, the tail of the flame sweeps the transverse wall where a slow post-oxidation process destroy the remaining $\mathrm{HC}$. This configuration is characterized by fuel and $\mathrm{HC}$ that are trapped in the corner of the crevice. The second combustion regime consists in a stabilized flame at the crevice entrance far from the bottom wall. The flame cannot propagate because of heat losses though the walls of the crevice. The flame thickness increases while fuel consumption decreases drastically but never stops. The fuel consumption occurs as the fuel diffuses to the burnt gases where it undergoes high temperatures.

\subsection{HC composition}

An analysis of the various $\mathrm{HC}$ families has been carried out in figure 15. It is possible to observe the time evolution of the percentage of each family (per unit of volume of the crevice). All configurations have been considered and the analysis of this figure may be divided in two parts : on the one hand, the still flames $(T=300 K$ and $T=400 K$ when $\left.y^{*}=3\right)$ and, on the other hand, the propagative flame $(T=400 K$ when $y^{*}=4$ and $y^{*}=5$, and $T=500 K$ for all width).

For the non-propagative cases (fig 15 - plots in the left column an bottom plot in the middle column), the amount of fuel converted into $\mathrm{HC}$ is mainly composed of paraffin (approximatively $96 \%$ ) and the $\mathrm{HC}$ composition is similar whatever the width and the temperature of the crevice. It is an expected result since the still flame structure remains the same. Time evolution of the mass fraction of the total 
$\mathrm{HC}$ have been plotted in figure 16 for the propagating flames (case A) and the still flames (case $\mathrm{B}$ ). Concerning case $\mathrm{B}$, very few total $\mathrm{HC}$ are converted into $\mathrm{CO} / \mathrm{CO}_{2}$ : between $10 \%$ and $20 \%$ of the initial fuel mass fraction when $y^{*}=3$ or 4 . When $y^{*}=5$ and $T=300 \mathrm{~K}$ it is possible to observe a flame that begins to propagate (Fig. 16-(b)). However, it extinguishes very quickly because the heat losses at the walls are prevalent compared to the energy production during the combustion. It corresponds to the top-left case in figure 15. This flame is a transition case between still and propagating cases. The paraffin undergoes a decrease of $10 \%$ of the total $\mathrm{HC}$ whereas it does not exceed $5 \%$ when the flame remains perfectly still. This drop concerns also the total HC mass fraction (Fig. 16-(b)), which decreases down to $65 \%$ of the initial mass of fuel before reaching a stationnary value when extinction occurs. Total HC of perfectly still flames remains up to $85 \%$ of the initial mass of fuel.

As far as propagating flames are concerned, the global HC concentration is lower because of a more complete oxidation. Indeed, as it may be seen in figure 16-(a), final total HC mass fractions reach very low levels : 3 to $10 \%$ of the initial fuel mass fraction. The repartition of the HC families is also different than when the flame is still. The central plot in figure $15\left(y^{*}=4\right.$ and $\left.T=400 \mathrm{~K}\right)$ represents the first propagating flame considering the temperature and the width of the crevice. The other propagating flame cases are depicted by the top figure in the central column and figures of the right column.

It is possible to observe in the end of the simulation a sudden decrease of paraffin. A similar variation occurs much more earlier if the crevice temperature is high (right column). It corresponds to the quenching instant of the flame. The paraffin is now down to $30 \%$ and the general repartition of $\mathrm{HC}$ families is $1 / 3$ of paraffin, $1 / 3$ of olefin and $1 / 3$ of others species (containing radicals, acetylenic and oxygenate). When $T=500 K, y^{*}=4$ and $y^{*}=5$, the same observation than when $T=400 K$ is made: in the conditions of the simulations, the width of the crevice plays a minor role in the $\mathrm{HC}$ composition compared to the temperature level (the $\mathrm{HC}$ composition is very close when $y^{*}=4$ and $y^{*}=5$ ).

These results may be summarized in the diagram presented in figure 17. The two flame modes (still flame and propagating flame) have been represented as a function of the temperature and the crevice thickness. The HC families repartition is indicated as well. For the highest temperatures and largest crevice thickness, a constant limit Peclet number is reached and the black line with white dots indicates the frontier beyond which the Peclet number is much more sensitive to the geometrical and thermodynamic properties of the crevice. Note that the frontiers between the combustion modes in the diagram have been approximatively plotted. Numerous simulations would be necessary to refine them. 
The above global analysis may be completed by scrutinizing locally the various HC levels for case $T=400 K$ and $y^{*}=5$ in various locations in the crevice. Four analysis surfaces have been placed in the domain. They may be seen in figure 18 . The height of the surfaces is equal to the reference laminar flame thickness $\left(\delta_{f}\right)$ and the width is $\delta_{f} / 2$, except for $S_{3}$ that is located in the crevice corner. Its height and width are both equal to $\delta_{f}$. Surface $S_{4}$ is considered as a reference. It is located in the center of the domain, far from the walls. $S_{1}$ is along the lateral wall half-way from the end of the crevice. $S_{2}$ is placed along the bottom wall of the crevice. An average of the mass fraction of each species is carried out in the surfaces. Time evolution of the various unburnt HC families has been plotted in figure 19.

The paraffin or fuel (top-left) evolution shows the flame propagation in the domain. The first surface to be reached by the flame is $S_{4}$, which is at the domain center. $S_{1}$ is at the same level but close to the wall and because of the heat losses, there is a delay before the flame appears. When it occurs, approximatively at the same time, the flame reaches surface $S_{2}$ at the bottom of the crevice and, finally, the paraffin decreases in the crevice corner represented by surface $S_{3}$. It is possible to observe that all the fuel is oxidized close to the walls $\left(S_{1}\right.$ and $\left.S_{2}\right)$, except in the corner $\left(S_{3}\right)$ where the heat losses are to important to sustain the oxidation process. Approximatively half of the initial fuel quantity remains trapped in the corners. Evolution of unburnt $\mathrm{HC}$ (top-right) shows two phases : formation and then, destruction. Concerning $S_{4}$ surface, these phases are quick. But, close to the walls, formation and especially destruction, takes more time. It is also possible to observe that the level of $\mathrm{HC}$ formed in surface $S_{1}$ and $S_{2}$ are similar. Concerning the corner $\left(S_{3}\right)$ there is less $\mathrm{HC}$ because of the remaining fuel that is not oxidized. A diffusion process can modify very slowly these levels. Concerning the HC, olefin, radicals and oxygenates in surfaces $S_{1}$ and $S_{2}$ have a maximum level similar to $S_{4}$, which is the reference surface far from the walls. On the other hand, a strong diminution of acetylenic mass fraction is induced by the presence of the walls.

It appears that the unburnt $\mathrm{HC}$ composition is similar for a given wall surface (lateral or bottom wall) and therefore for a given heat transfer. Concerning the corner $\left(S_{3}\right)$, unburnt $\mathrm{HC}$ composition is different with a strong proportion of olefin and oxygenate compared to surfaces $S_{1}$ an $S_{2}$. On the other hand, acetylenic and radicals are present in similar proportions.

\section{Conclusions}

Numerical simulations of laminar flames have been carried out to study HOQ of flames onto planar walls and in a crevice configuration at atmospheric pressure. A 
skeletal reaction mechanisms was used to describe combustion of iso-octane. In a first part, comparisons with a detailed mechanisms show that the skeletal mechanism is able to estimate correctly the concentrations of the major families of HC, total $\mathrm{HC}$ and the general flame properties: temperature profile, velocity. Then HOQ configuration has been studied for various wall temperatures and mixture equivalence ratios. It appeared that the quenching Peclet number and wall heat flux showed very good agreements with precedent studies [24, 31]. The use of a multi-step mechanism allowed to measure the impact of the heat transfers at the wall on the formation of HC. Eventually, it appeared that the $\mathrm{HC}$ composition is generally around 1/3 of olefin, $1 / 3$ of radicals and $1 / 3$ of acetylenic. The study has been extended to the analysis of $\mathrm{HC}$ formation in crevices thanks to $2 \mathrm{D}$ simulations with complex chemistry. The varying parameters of the simulations are the crevice temperature and thicknesses. Two combustion regimes have been observed : the still flame that is stopped close to the entrance of the crevice and the propagating flame that is able to reach the bottom wall where it is quenched. In the first case a diffusion regime appears between the fresh gases and the $\mathrm{HC}$ emitted by the still flame front while, in the second case, HC may be detected along the transverse wall and in the corner of the crevice before disappearing in a slow diffusion/oxidation process. Eventually, HC composition and mass fraction has been studied and all the results have been summarized in a diagram. Global and local analysis have been carried out. It appears that unburnt $\mathrm{HC}$ famillies close to the walls remain similar except in the corners where heat transfers prevent the complete oxidation of the fuel. Although the behaviour of 1D HOQ has been observed for propagating flame along the central axis, the peculiar behaviour of gas trapped in the corners can be captured only thanks to multidimensional configurations. These results have been obtained in a simplified configuration far from the realistic conditions of an engines. However, it allowed us to focus on very specific interactions between wall heat transfers and unburnt $\mathrm{HC}$ formation.

This study shows that the production of $\mathrm{HC}$ due to the interaction of a flame with a wall in a confined geometry can be divided in three parts. First, a flame can propagates directly toward the wall. This configuration corresponds to the 1D HOQ. Second a flame can propagate tangentially to a wall, contacts take place on the edge of the flame that sweeps the wall. Third, a flame reaches a cavity where the wall surface per unit of gas volume is so high that the flame cannot propagate because of heat transfer. This can be the case of small crevices or corners. The first cases can be studied with $1 \mathrm{D}$ simulations but the other cases require at least $2 \mathrm{D}$ simulations. The 1D HOQ is a widely used configuration. It has been utilized as a reference geometry in our work to validate the quenching distances but also to detail the mechanism of 
$\mathrm{HC}$ formation. First, the fuel is converted into $\mathrm{HC}$ then $\mathrm{HC}$ are oxidized to $\mathrm{CO} / \mathrm{CO} 2$. The first step is less influenced by heat wall transfer that HC final oxidation. With a freely propagating flame, both chemical steps occur quickly and a small amount of $\mathrm{HC}$ exists within the flame front, which is generally quite thin. Wall heat transfer affects preferentially the $\mathrm{HC}$ oxidation. Accordingly, $\mathrm{HOQ}$ promote the $\mathrm{HC}$ formation because the rate of conversion of fuel into $\mathrm{HC}$ becomes higher than the oxidation rate of the produced HC. The edge of flame, which propagates tangentially to the wall, experiences similar phenomena than those occurring in the HOQ: oxidation of $\mathrm{HC}$ is weakened because of the wall heat transfer. A direct consequence is the thickening of the flame at the wall and an increase of the amount of HC. Quenching is identical to $\mathrm{HOQ}$ : corresponding Peclet number and $\mathrm{HC}$ composition are similar in both cases. In the latter case the flame is not able to propagate because the heat transfer to the wall is too great. Thus, even the first chemical step (conversion of fuel to $\mathrm{HC}$ ) is blocked. As a consequence a large amount of total $\mathrm{HC}$ is present in these areas, but the composition is mainly pure fuel (paraffin). Finally it is important to notice that in all cases presented here, hot burnt gases were surrounding the total HC. Consequently HC will be mixed to these burnt gases trough different mixing processes (diffusion, convection, ), ultimately, because of the high temperatures they will be completely oxidized. But delays vary a lot. It is very quick for a freely propagating flame and it increases for HOQ and flame propagating tangentially to the wall. Therefore, it depends strongly of the geometry of the crevice. The delay is driven by a very slow diffusion process, therefore simulations were not conducted up to the total consumption of $\mathrm{HC}$. Accordingly, to determine the amount of $\mathrm{HC}$ in the exhaust gas of an actual engine it is necessarily to take into account the evolution of the surrounding gas thermodynamic properties. Indeed, if the temperature decreases (for instance during the decompression of an engine) it may reach a point where unburnt $\mathrm{HC}$ will not be oxidized anymore leading to a high level of $\mathrm{HC}$ emission. Future works plan to take into account the pressure increase in the chamber and turbulent flame/wall interactions outside the crevice.

\section{References}

[1] A.A. Adamczyk. Oxidation of the piston crevice hydrocarbon during the expansion process in a spark ignition engine. Combustion Science and Technology, 64:263-276, 1989.

[2] A.A. Adamczyk, E.W. Kaiser, J.A. Cavolowsky, and G.A. Lovie. In Pittsburgh The combustion institute, editor, Proceedings of the Combustion Institute, vol. 
18, pages 6341-6349, 1981.

[3] A.C. Alkidas, R.J. Drews, and W.F. Miller. Effects of piston crevice geometry of the steady-state engine-out hydrocarbons emissions of a s.i. engine. SAE transaction, 103(3):2437-2458, 1995.

[4] C. Angelberger. Contribution à la Modélisation de Interation FlammeParoi et des Flux Pariétaux dans les Moteurs Allumage Commandé. PhD thesis, INPT, France, 1997.

[5] R.J. Blint and J.H. Bechtel. Hydrocarbon combustion near a cooled wall. SAE paper, (820063), 1982.

[6] D.J. Boam, I.C. Finlay, T.W. Biddulph, T. Ma, R. Lee, S. H. Richardson, J. Bloomfield, and J.A. Green. The sources of unburnt hydrocarbon emissions from spark ignition engines during cold starts and warm-up. In Journal of automobile engineering, editor, Proceedings of the Institution of Mechanical Engineers. Part D, pages 1-11, 1994.

[7] D. Bradley, R.A. Hicks, M. Lawes, C. G.W. Sheppard, and R. Wooley. Combustion and Flame, 115:126-144, 1998.

[8] P.N. Brown, G.D. Byrne, and A.C. Hindmarsh. Vode: A variable coefficient ode solver. SIAM J. Sci. Stat. Computing, 10:1038-1051, 1989.

[9] G. Bruneaux. Etude Numérique de linteraction flame parois. PhD thesis, Ecole Centrale Paris, 1996.

[10] G. Bruneaux, K. Akselvoll, T. Poinsot, and J.H. Ferziger. Flame-wall interaction simulation in a turbulent channel flow. Combustion and Flame, 107:22-44, 1995.

[11] W.B. Bush, F.E. Fendel, and S.F Fink. In-cylinder measurements of wall layer hydrocarbons in a spark ignited engine. Combustion Science and Technology, 24:53-70, 1980.

[12] M. Chauvy, L. Duchamp de Lageneste, A. Mura, F.X. Demoulin, and J. Reveillon. Hc in ic engines : Modelling of the hc formation in a pasr. In European Combustion Meeting, 2007.

[13] W.K. Cheng, D. Hamrim, J.B. Heywood, S. Hochgrb, K. Min, and M. Norris. An overview of hydrocarbon emissions in spark-ignition engines. SAE Paper 9327081, 1993. 
[14] H.J. Curran, P. Gaffuri, W.J. Pitz, and C. K. Westbrook. A comprehensive modeling study of iso-octane oxidation. Combustion and Flame, 129:253-280, 2002 .

[15] W.A. Daniel. In Pittsburgh The combustion institute, editor, Proceedings of the Combustion Institute, vol. 6, pages 886-894, 1956.

[16] G. Desoutter. Etude Numérique de la Propagation dune Flamme sous IInfluence dun Film Liquide de Carburant sur la Paroi. PhD thesis, Institut National Polytechnique de Toulouse, France, 2007.

[17] F.L. Dryer and K. Brezinsky. A flow reactor study of the oxidation of n-octane and iso-octane. Combustion Science and Technology, 45(3):199-212, 1986.

[18] O.A. Ezekoye, R. Greif, and D. Lee. Increased surface temperature effects on wall heat transfer duringunsteady flame quenching. In Pittsburgh The combustion institute, editor, Proceedings of the Combustion Institute, vol. 24, page 1465, 1992.

[19] O.A. Ezekoye, R. Greif, and R.F. Sawyer. Increased surface temperature effects on wall heat transfer during unsteady flame quenching. In Pittsburgh The combustion institute, editor, Proceedings of the Combustion Institute, vol. 24, pages 85-90, 1992.

[20] G.R. Ferguson and J.C. Keck. Combustion and Flame, 28:197-205, 1977.

[21] G.R. Ferguson and J.C. Keck. Combustion and Flame, 24:85-98, 1979.

[22] J.C. Guibet. Carburants et Moteurs. Technip, 1987.

[23] J.C. Guibet. Les carburants et la combustion. Number BM 2520. Technologie de lingénieur, 2000.

[24] C. Hasse, M. Bollig, N. Peters, and H.A. Dwyer. Quenching of laminar isooctane flames at cold walls. Combustion and Flame, 122:117-129, 2000.

[25] N.A. Henein and M. K.Tagomori. Cold-start hydrocarbon emissions in portinjected gasoline engines. Progess in Energy and Combustion Science, 25:563593, 1999.

[26] J.B. Heywood. International combustion engine fundamentals. McGraw-Hill, 1988. 
[27] W. Hocks, N. Peters, and G. Adomeit. Flame quenching in front of a cold wall under two-steps kinetics. Combustion and Flame, 41:157-170, 1981.

[28] W M. Huang, S.R. Vosen, and R. Greif. In Pittsburgh The combustion institute, editor, Proceedings of the Combustion Institute, vol. 21, pages 1853-1860, 1986.

[29] J. Jarosinski. A survey of recent studies on flame extinction. Combustion Science and Technology, 12:81-116, 1986.

[30] R.J. Kee, F.M. Rupley, and J. A. Miller. Chemkin ii: A fortran chemical kinetics package for the analysis of gas-phase chemical kinetics. Technical report, Sandia Report, SAND 89-8009, 1989.

[31] T.M. Kiehne, R.D. Matthews, and D.E. Wilson. In Pittsburgh The combustion institute, editor, Proceedings of the Combustion Institute, vol. 21, pages 481489, 1986.

[32] G.A. Lavoie. Correlations of combustion data for s.i. engine calculations-laminar flame speed, quench distance and global reaction rates. SAE paper, (780229), 1978.

[33] S.K. Lele. Compact finite difference schemes with spectral like resolution. J. Comput. Phys., (103):16-42, 1992.

[34] J.A. LoRusso, E.W. Kaiser, and G.A. Lavoie. In-cylinder measurements of wall layer hydrocarbons in a spark ignited engine. Combustion Science and Technology, 33:75-112, 1983.

[35] J.A. LoRusso, G.A. Lavoie, and E.W. Kaiser. An electrohydraulic gas sampling valve with application emission studies. SAE paper, (80045), 1980.

[36] J.H. Lu, O.A. Ezekoye, R. Greif, and R.F. Sawyer. Unsteady heat transfer during side wall quenching of a laminar flame. In Pittsburgh The combustion institute, editor, Proceedings of the Combustion Institute, vol. 23, pages 441-446, 1990.

[37] K. Min and W.K. Cheng. Oxidation of the piston crevice hydrocarbon during the expansion process in a spark ignition engine. Combustion Science and Technology, 106:307-326, 1995.

[38] R. Ogink and V. Golovitchev. Computer Modelling of HCCI Combustion. PhD thesis, Divison of Thermo and Fluid Dynamics, Chalmers University, Gothenburg, Sweden, 2004. 
[39] N. Peters. Abschlubericht zum dfg forschungsvorhaben pe 241/9-2, available on the world wide web http://www.itm.rwth-aachen.de, rwth-aachen. Technical report, Institut fr Technische Mechanik, D-52056 Aachen, Germany.

[40] T. Poinsot, D. Haworth, and G. Bruneaux. A law of the wall model for turbulent premixed combustion. Combustion and Flame, 95:118-133, 1993.

[41] T. Poinsot and D. Veynante. Theoretical and Numerical Combustion, second edition. Edwards, 2005.

[42] S.B. Pope. Computationally efficient implementation of combustion chemistry using in situ adaptative tabulation. Combustion Theory and Modeling, 1(1):4163, 1997.

[43] P. Popp and M. Baum. Analysis of wall heat fluxes, reaction mechanisms, and unburnt hydrocarbons during the head-on quenching of laminar methane flame. Combustion and Flame, 108:327-348, 1997.

[44] P. Popp, M. Baum, M. Hilka, and T. Poinsot. A numerical study of laminar flame wall interaction with detailed chemistry: wall temperature effects. Technical report, Rapport du Centre de Recherche sur la Combustion Turbulente. Technip, Rueil-Malmaison, 1996.

[45] P. Popp, M. Smooke, and M. Baum. In Pittsburgh The combustion institute, editor, Proceedings of the Combustion Institute, vol. 26, pages 2693-2700, 1996.

[46] J.T. Wentworth. The piston crevice volume effect on exhaust hydrocarbon emissions. Combustion Science and Technology, 4:97, 1971.

[47] C.K. Westbrook, A.A. Adamczyk, and G.A. Lavoie. A numerical study of laminar flame wall quenching. Combustion and Flame, 40:81-99, 1981.

[48] A. A. Wray. Minimal storage time-advancement schemes for spectral methods. Technical report, Center for turbulence research Report, Stanford University, 1990 . 


\begin{tabular}{|c|c|}
\hline Paraffin & IC8H18 \\
\hline Olefin & $\mathrm{C} 2 \mathrm{H} 4, \mathrm{C} 3 \mathrm{H} 6, \mathrm{IC} 4 \mathrm{H} 8$ \\
\hline Acetylenic & $\mathrm{C} 2 \mathrm{H} 2, \mathrm{C} 3 \mathrm{H}$ \\
\hline Oxygenate & $\mathrm{CH} 2 \mathrm{O}$ \\
\hline Radicals & $\begin{array}{c}\mathrm{CHO}, \mathrm{CH} 2, \mathrm{CH} 3, \mathrm{C} 2 \mathrm{H} 3, \mathrm{C} 3 \mathrm{H} 5 \\
\text { IC3H7, NC3H7, IC4H7, IC4H9 } \\
\text { TC4H9, AC8H17, CC8H17 }\end{array}$ \\
\hline
\end{tabular}

Table 1: HC families composition, Hasse's kinetics. 


\begin{tabular}{|c|c|c|}
\hline Wall Temperature $(\mathrm{K})$ & 400 & 500 \\
\hline$P_{e}$, LFS & 0.38 & 0.33 \\
\hline$P_{e}$, Hasse & 0.39 & 0.34 \\
\hline$\Phi_{Q}$, LFS & 0.50 & 0.51 \\
\hline$\Phi_{Q}$, Hasse & 0.43 & 0.46 \\
\hline
\end{tabular}

Table 2: Comparison of the Peclet numbers and heat fluxes. LFS : actual computations, Hasse : results from [24] 


\begin{tabular}{|c|c|c|c|c|c|}
\hline$t^{*}$ & Case a & Case b & Case c & Case d & Case e \\
\hline & $T=400 K$ & $T=400 K$ & $T=400 K$ & $T=300 K$ & $T=500 K$ \\
& $\Phi=1$ & $\Phi=0.8$ & $\Phi=1.4$ & $\Phi=1$ & $\Phi=1$ \\
\hline-1 & 1.00 & 1.00 & 1.00 & 1.00 & 1.00 \\
-0.2 & 0.40 & 0.39 & 0.55 & 0.41 & 0.42 \\
0 & 0.18 & 0.21 & 0.44 & 0.19 & 0.14 \\
0.2 & 0.06 & 0.17 & 0.37 & 0.08 & 0.02 \\
\hline
\end{tabular}

Table 3: Mass fraction of total HC normalized by the initial fuel mass fraction of each case. 


\begin{tabular}{|c|c|c|}
\hline Numerical configurations & Speed & Accuracy \\
\hline Global Chemistry+ strong coupling & $\star \star \star \star \star$ & - \\
\hline Complex Chemistry + strong coupling & - & $\star \star \star \star \star$ \\
\hline Complex Chemistry + weak coupling & $\star \star$ & $\star \star \star$ \\
\hline Complex Chemistry + ISAT + 'strong coupling & $\star$ & $\star \star \star \star$ \\
\hline Complex Chemistry + ISAT + 'weak coupling & $\star \star \star$ & $\star \star \star$ \\
\hline
\end{tabular}

Table 4: Evalutation of the computational cost and accuracy of the chemistry resolution. 


\begin{tabular}{|c|c|c|c|}
\hline $\mathrm{y}^{*}$ & 3 & 4 & 5 \\
\hline$T_{w}=300$ & $\mathrm{~B}-/$ & $\mathrm{B}-/$ & $\mathrm{B}-/$ \\
\hline$T_{w}=400$ & $\mathrm{~B}-/$ & $\mathrm{A}-P e=0.4$ & $\mathrm{~A}-P e=0.35$ \\
\hline$T_{w}=500$ & $\mathrm{~A}-P e=0.3$ & $\mathrm{~A}-P e=0.25$ & $\mathrm{~A}-P e=0.25$ \\
\hline
\end{tabular}

Table 5: Combustion modes and Peclet numbers for various crevice thickness and various $T_{\text {wall }}$. A : propagating flame, B : still flame. 

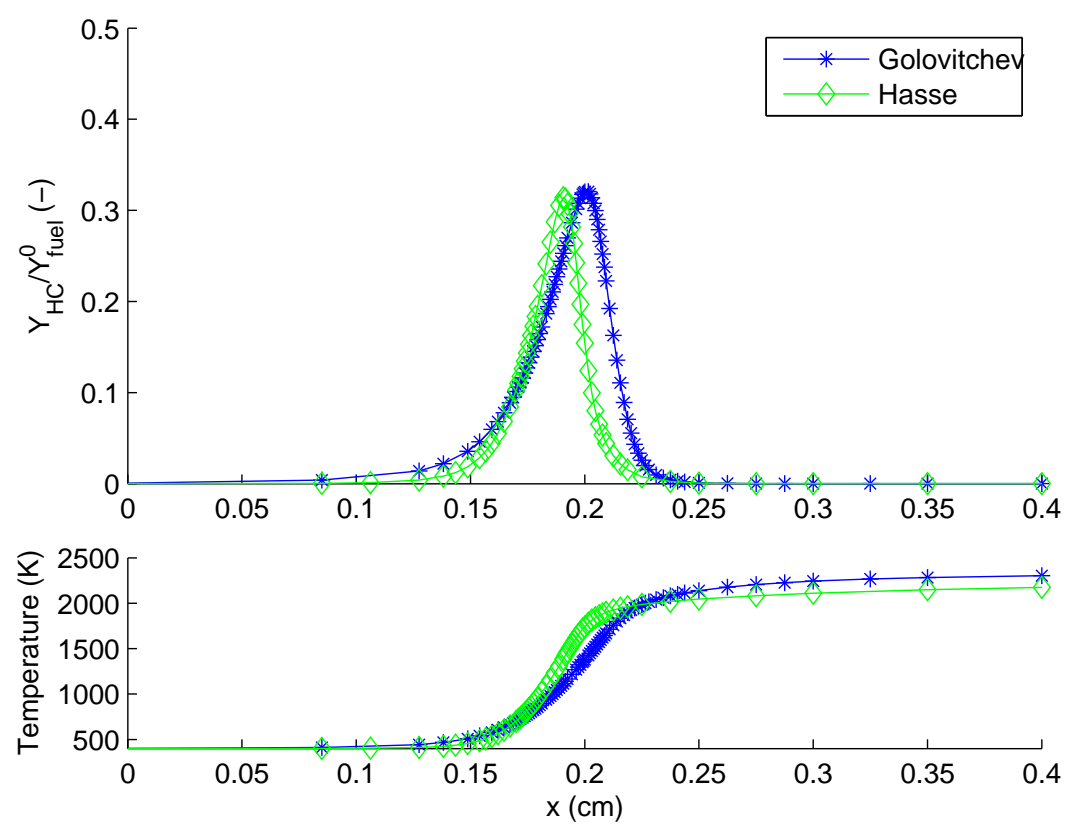

Figure 1: Spatial profiles of HC mass fraction (top) and temperature (bottom) through a laminar flame, mechanisms of Hasse and Golovitchev. 

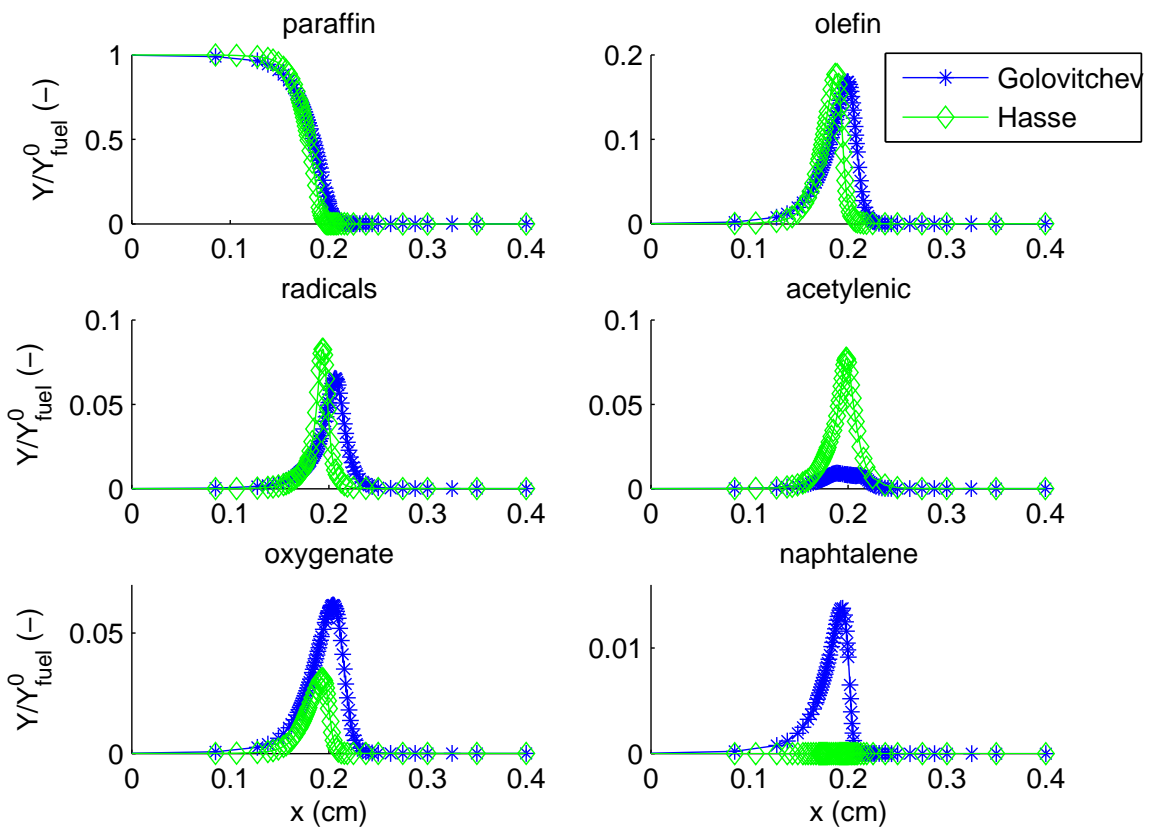

Figure 2: HC Families mass fraction profiles, mechanisms of Hasse and Golovitchev. 


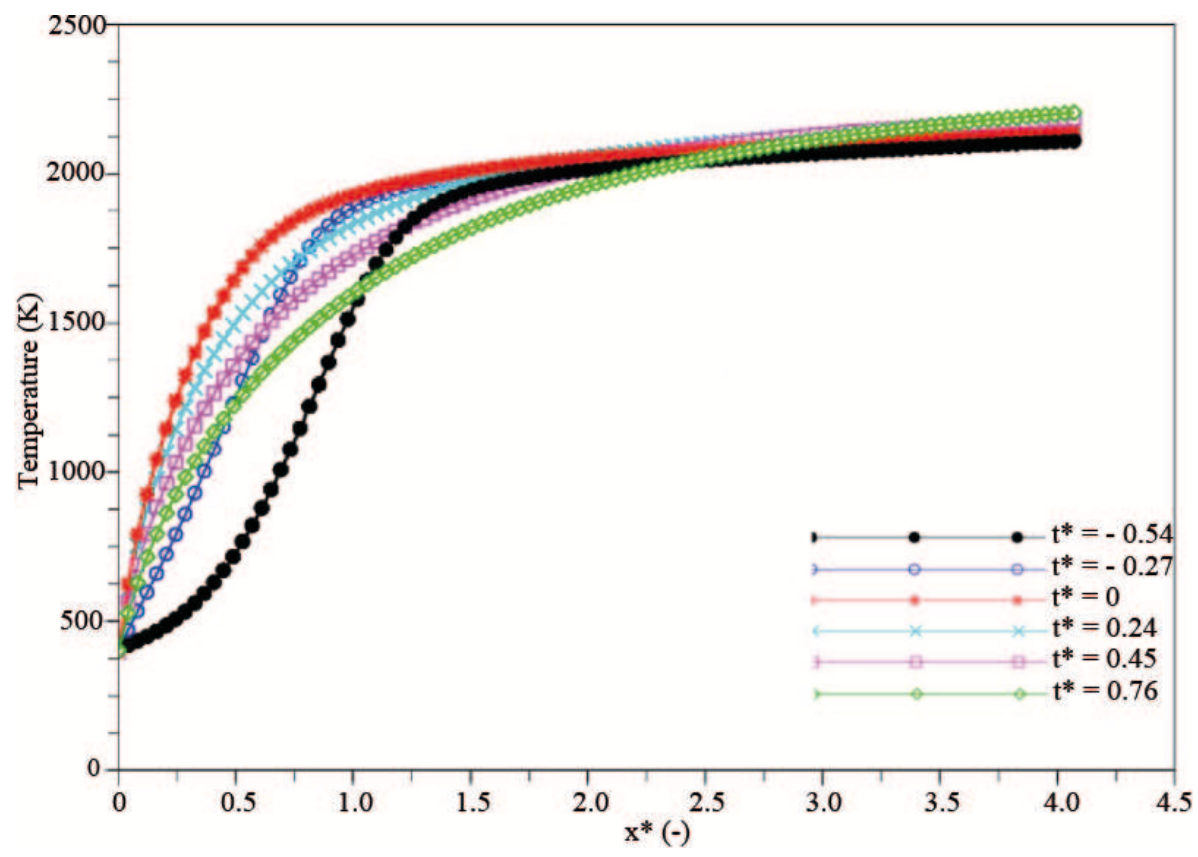

Figure 3: HOQ temperature profile for various time. 


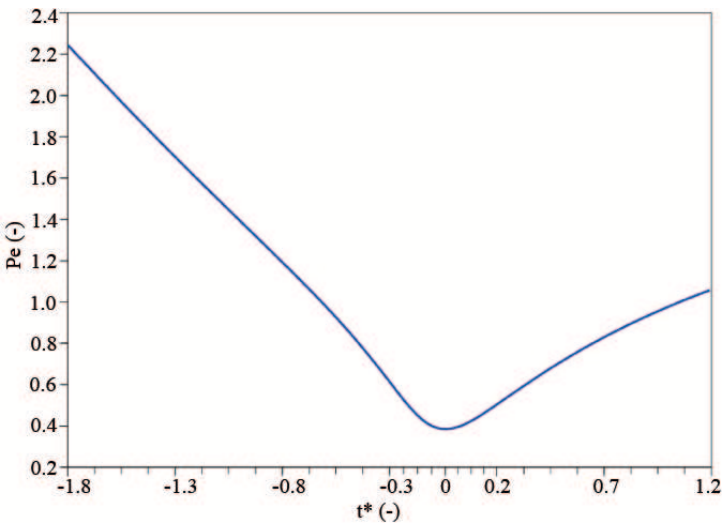

(a) - Peclet number

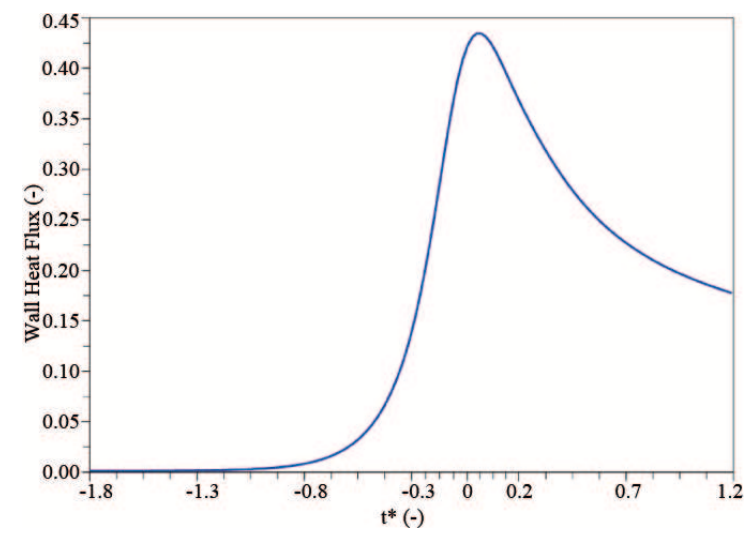

(b) -Wall heat flux

Figure 4: Time evolution of the Peclet number and the wall heat flux. 


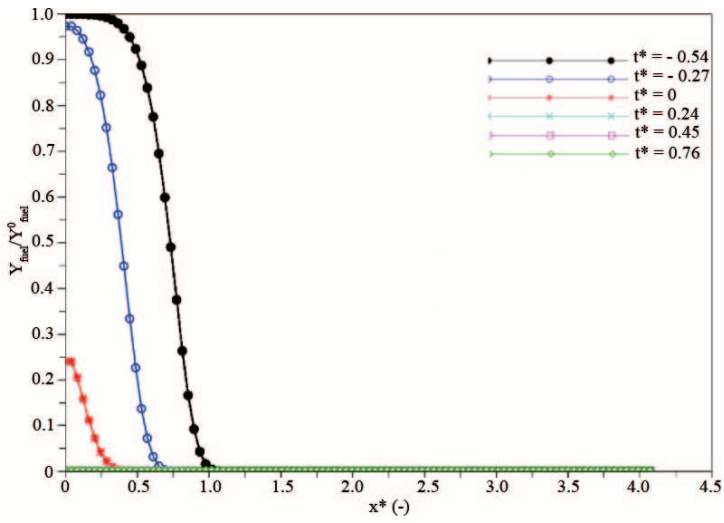

(a) - Fuel mass fraction

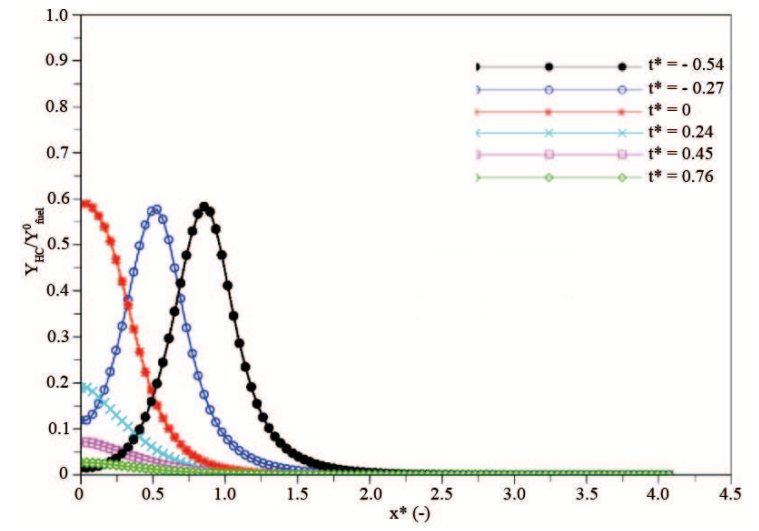

(b) - HC (except fuel) mass fraction

Figure 5: HOQ time evolution of the fuel and HC mass fractions. 

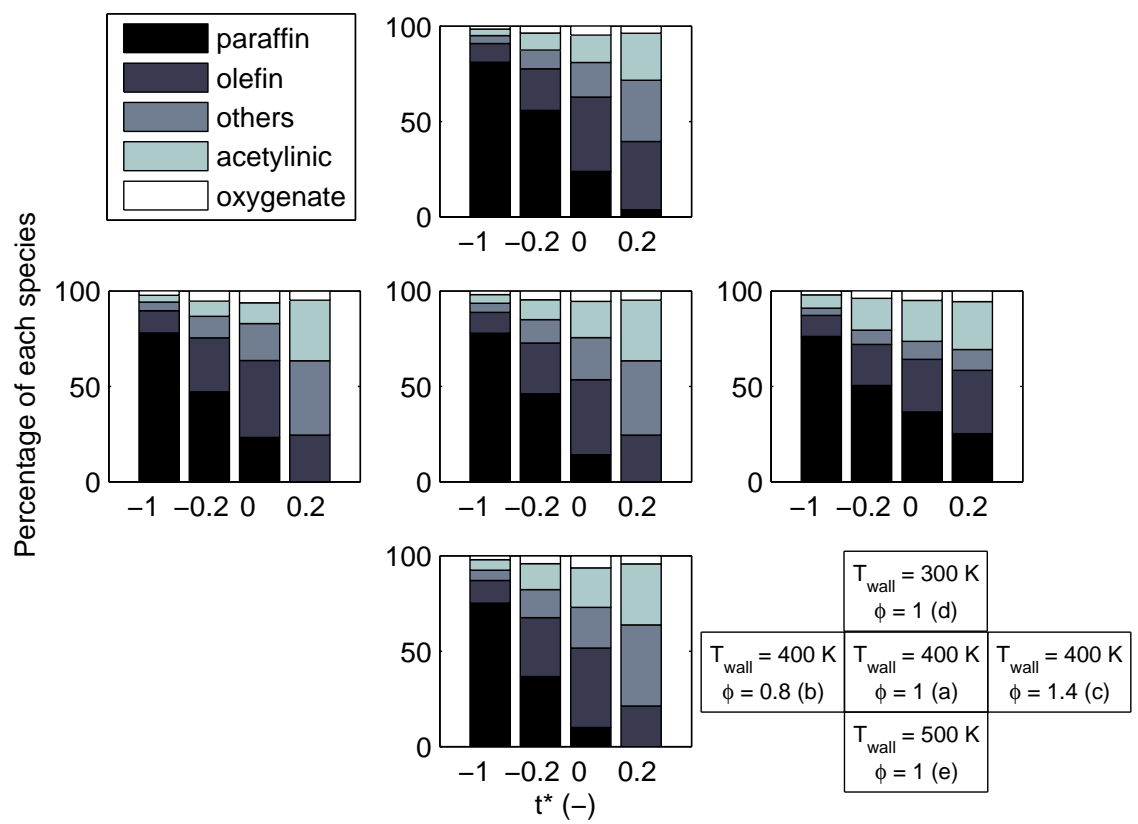

Figure 6: Percentage of each $\mathrm{HC}$ families present at four different normalized times for different equivalence ratio and wall temperature (subcase a: $T_{w}=400 \mathrm{~K}$ and $\Phi=1.0 ; \mathrm{b}: T_{w}=400 \mathrm{~K}$ and $\Phi=0.8 ; \mathrm{c}: T_{w}=400 \mathrm{~K}$ and $\Phi=1.4 ; \mathrm{d}: T_{w}=300 \mathrm{~K}$ and $\Phi=1.0 ;$ e: $T_{w}=500 K$ and $\Phi=1.0$ ) 

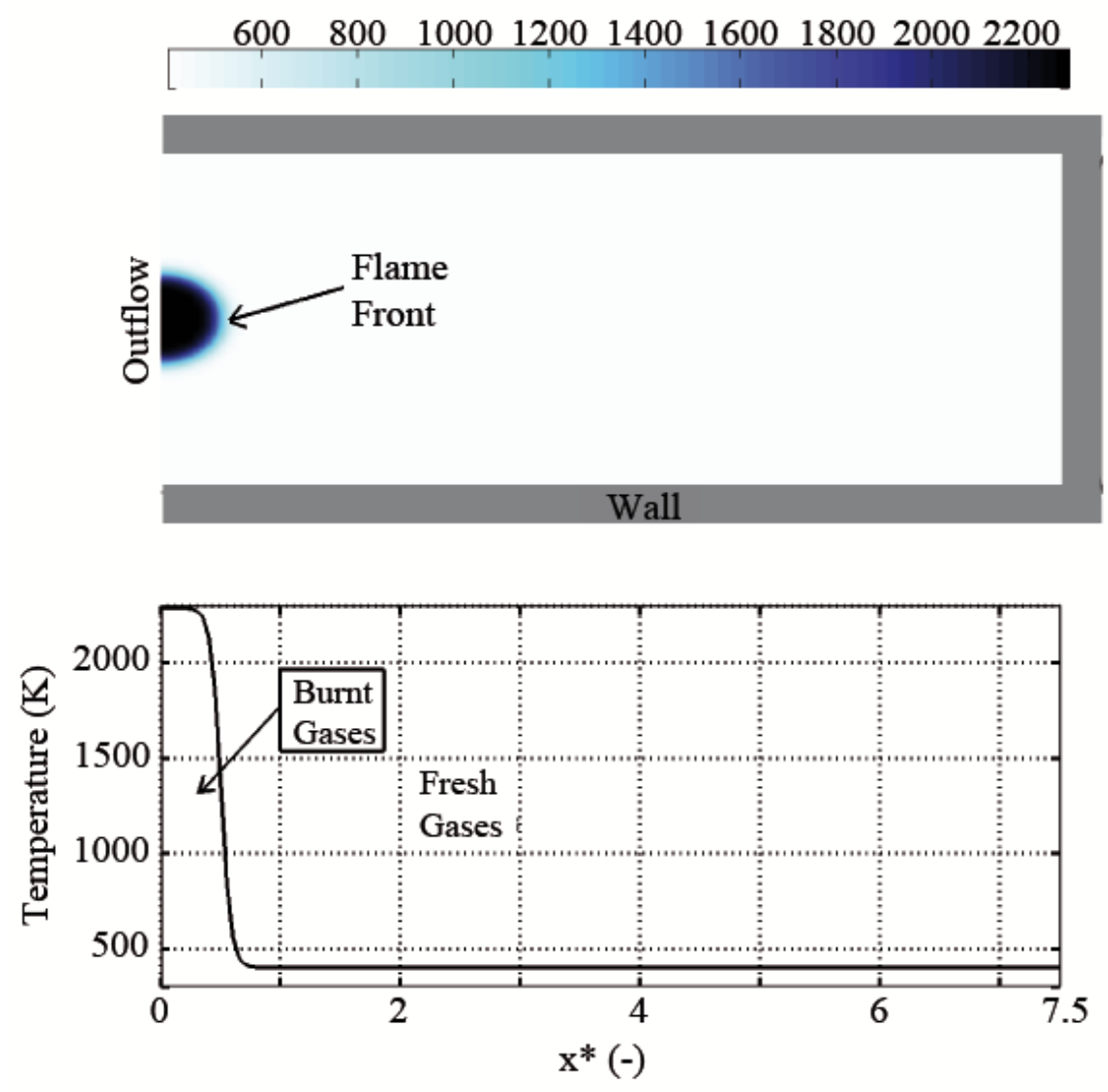

Figure 7: Crevice configuration 

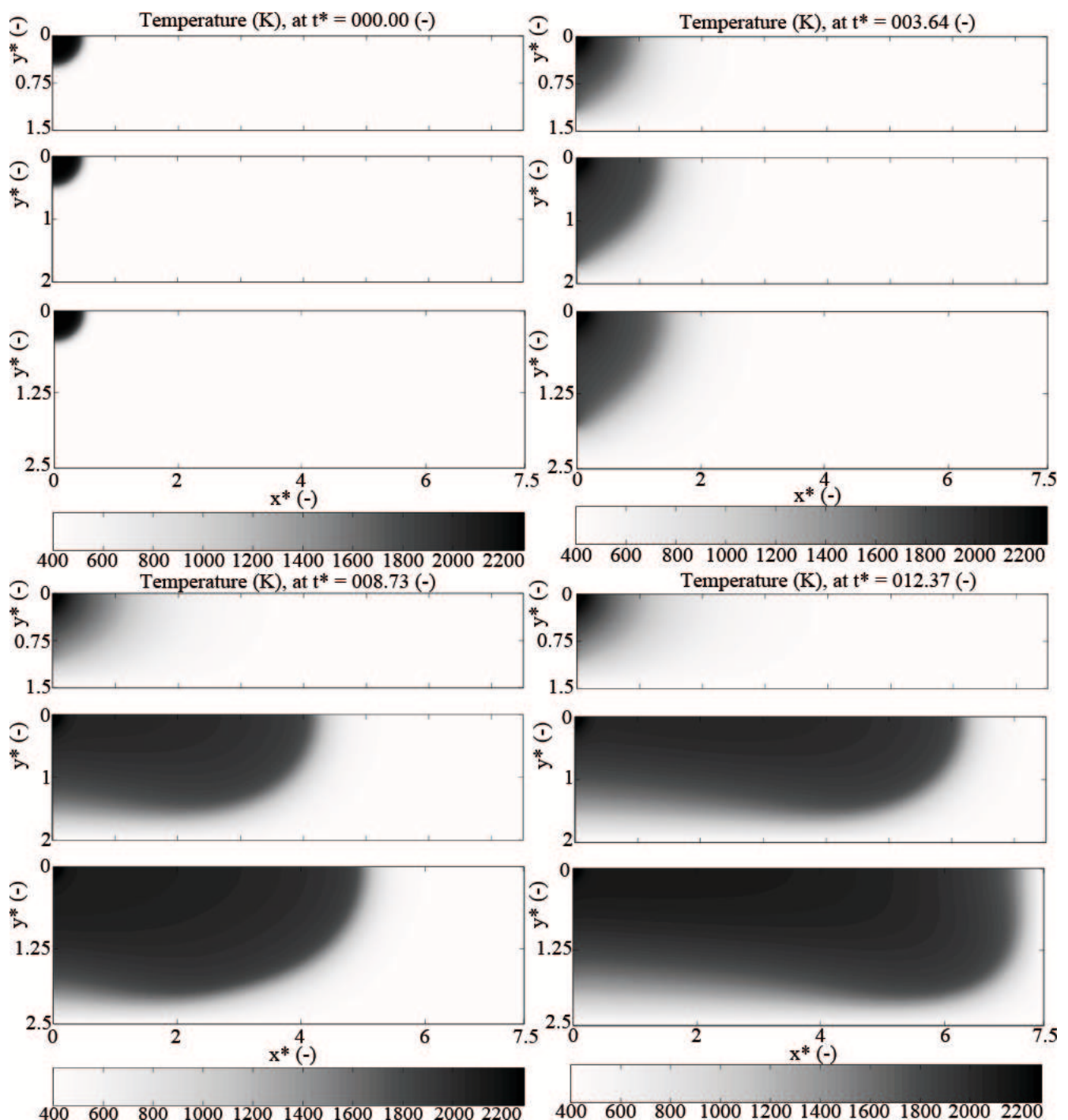

$\begin{array}{llllllllll}400 & 600 & 800 & 1000 & 1200 & 1400 & 1600 & 1800 & 2000 & 2200\end{array}$

$400 \quad 600 \quad 800 \quad 100012001400160018002000 \quad 2200$

Figure 8: Temperature time evolution for the three different thicknesses with $T_{w}=$ $400 K$. 

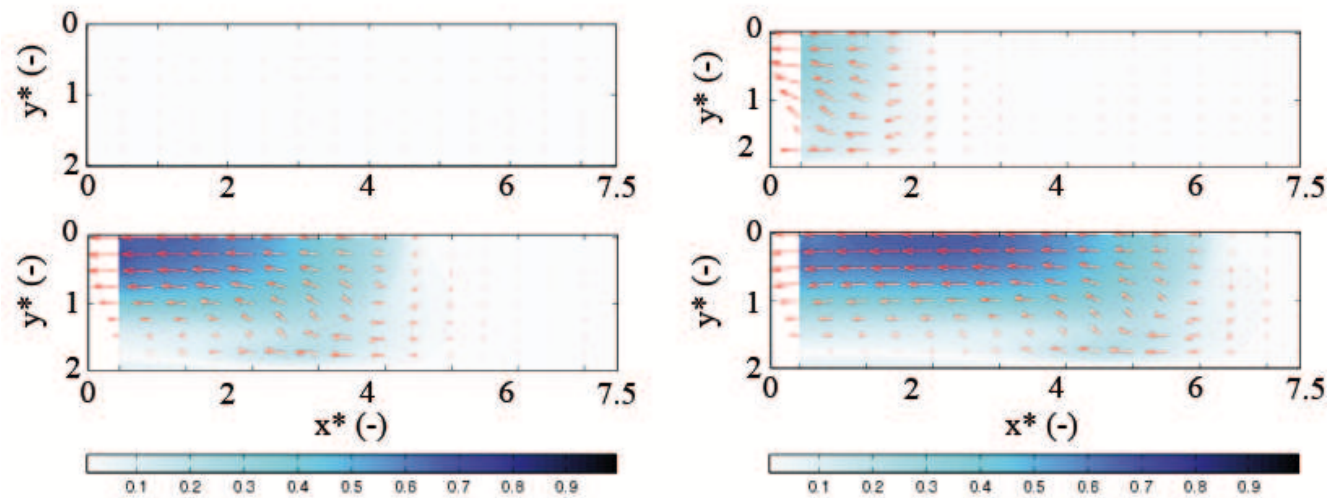

Figure 9: Example of a velocity field generated by the flame propagation inside the crevice : vectors and normalized modulus. Top left: $t^{*}=0$, top right: $t^{*}=3.78$, bottom left $t *=8.73$ and bottom right $t^{*}=12.23$. Case $T=400 K, y^{*}=4$. 


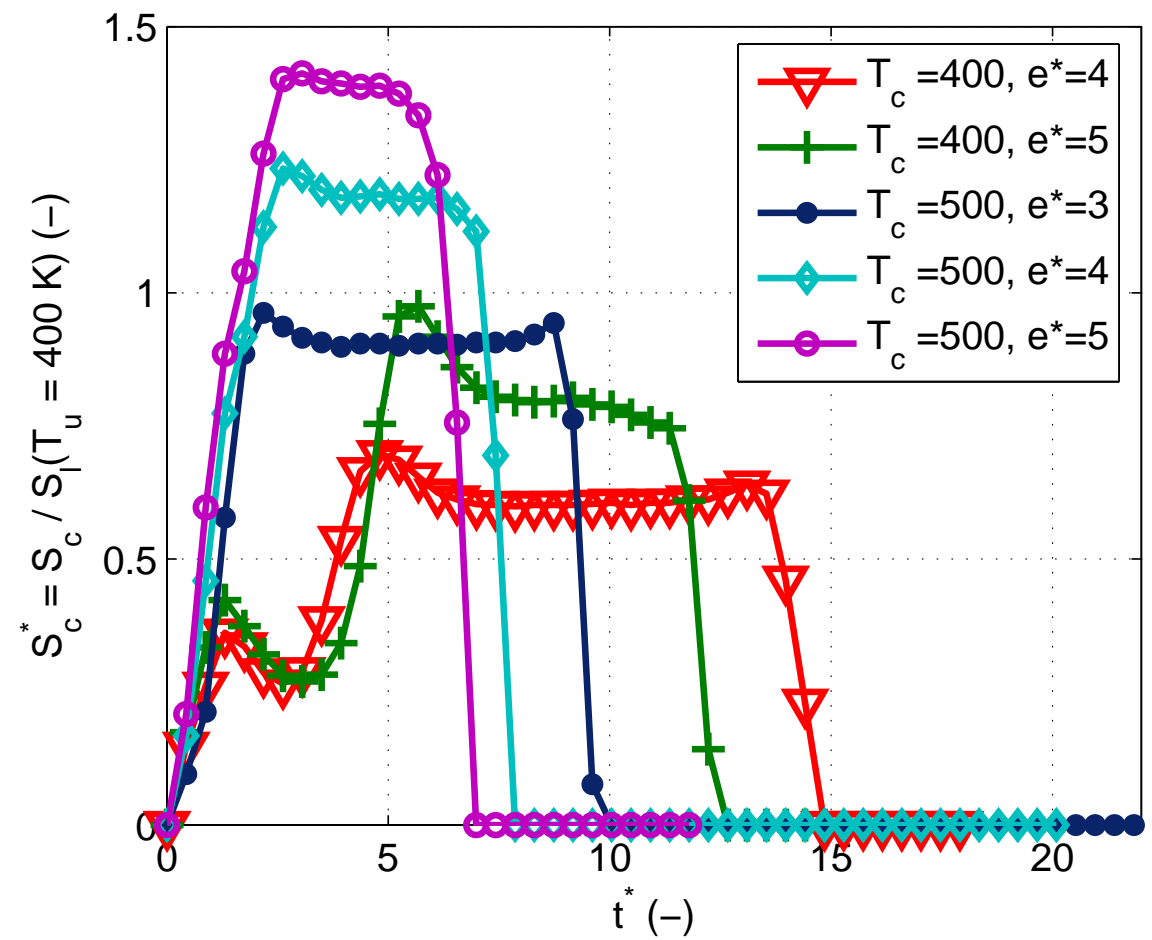

Figure 10: Normalized flame speed along the symetry axis. 


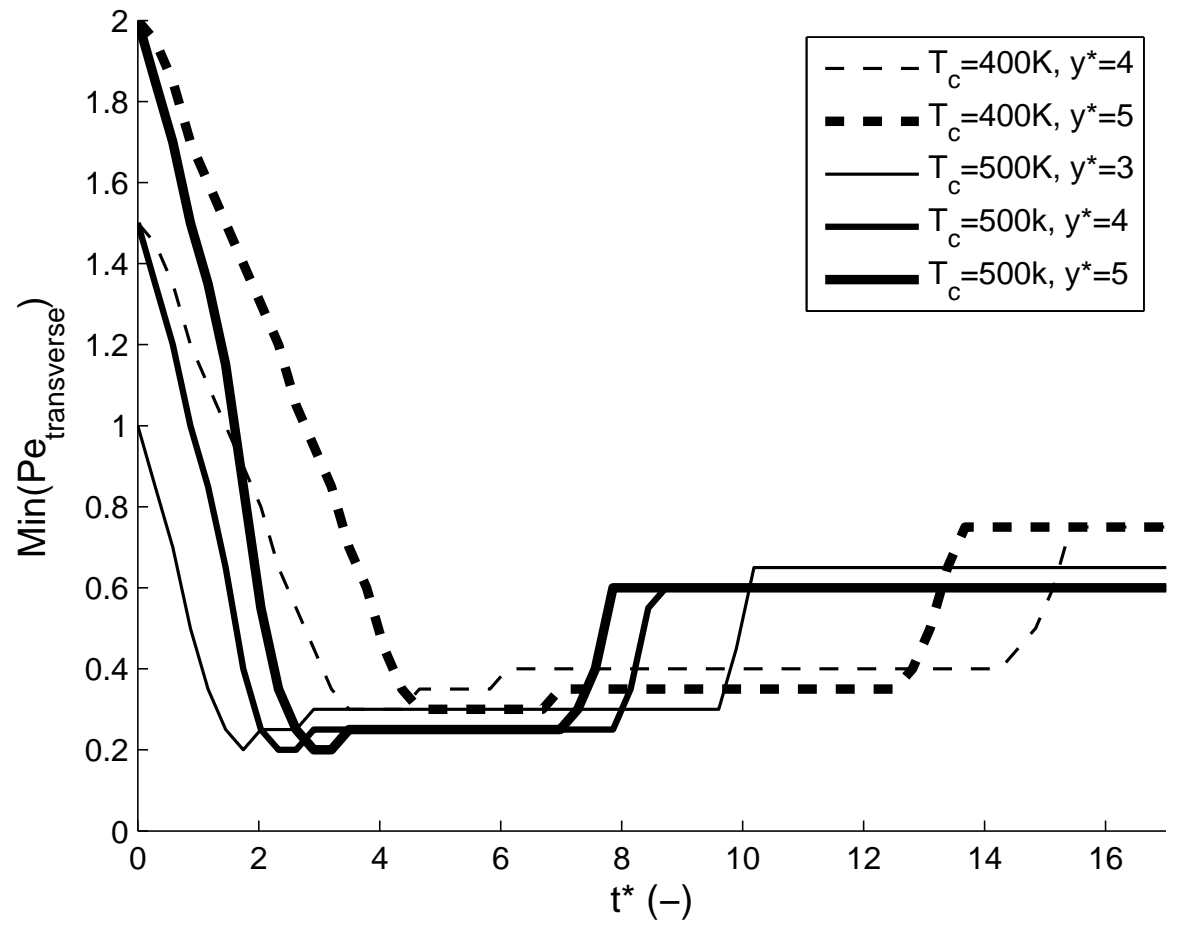

Figure 11: Minimum transverse Peclet number. 

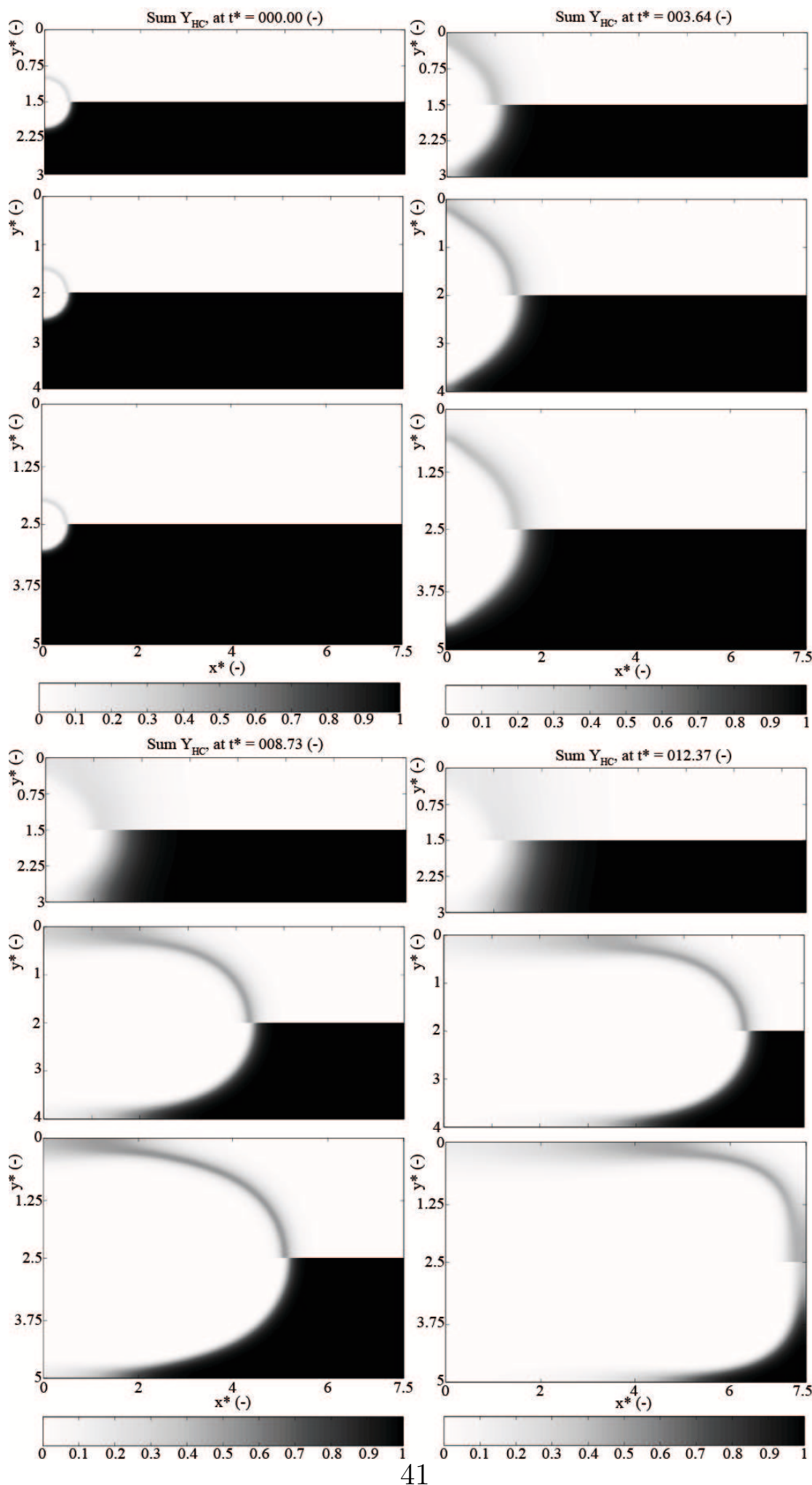

Figure 12: Time evolution of $\mathrm{HC}$ and fuel mass fraction. Crevice thickness: 3,4 and 5 and temperature: $T_{w}=400 \mathrm{~K}$. 


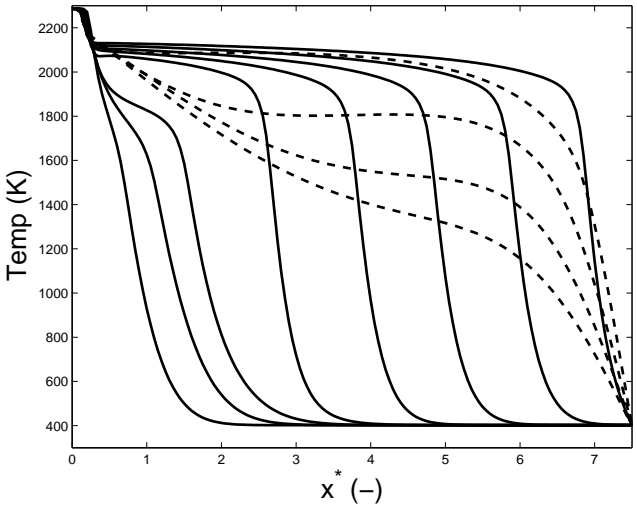

(a) - Propagating flame, $T=400 \mathrm{~K}$, $y^{*}=5$, dashed lines : post HOQ times

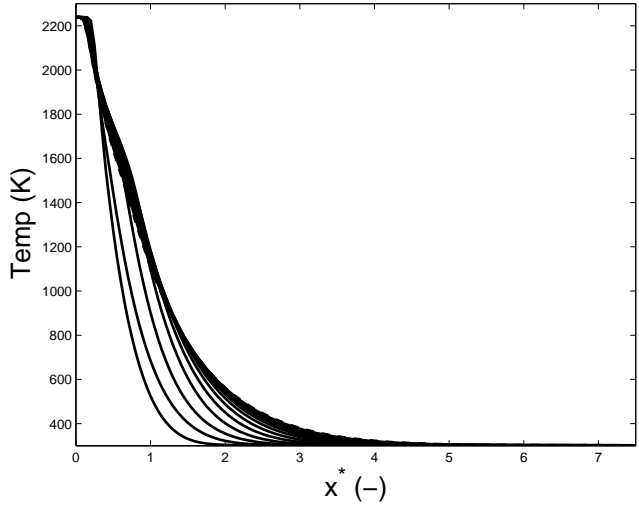

(b) - Still flame, $T=300 K, y^{*}=3$

Figure 13: Time evolution (from left to right) of the temperature profile along the symmetry axis of the crevice. 

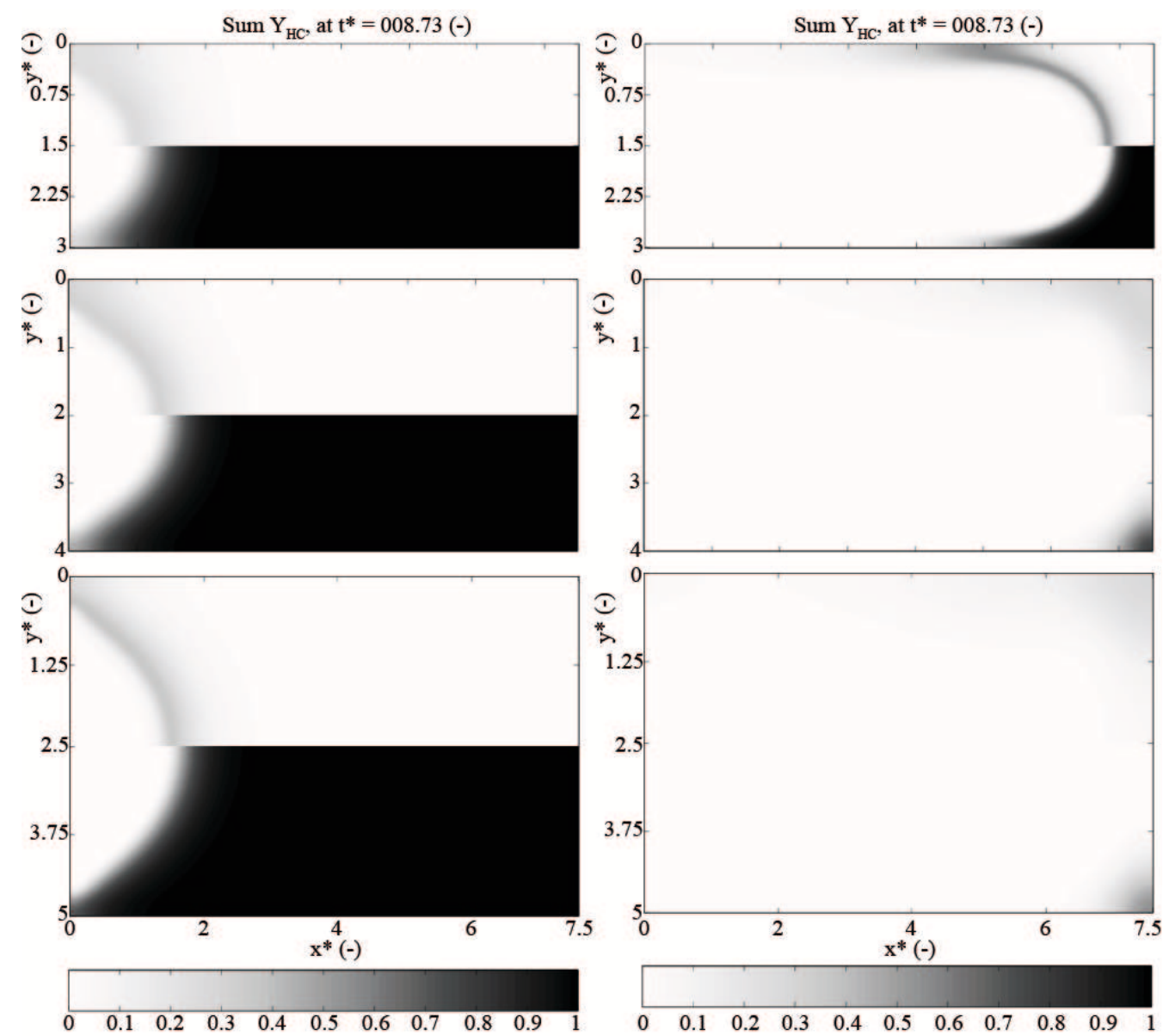

Figure 14: Mass fraction of $\mathrm{HC}$ and fuel. Crevice thickness: 3,4 and 5 and temperature: $T_{w}=300 \mathrm{~K}$ (left), $T_{w}=500 \mathrm{~K}$ (right), post-quenching period, time $t^{*}=8.73$. 

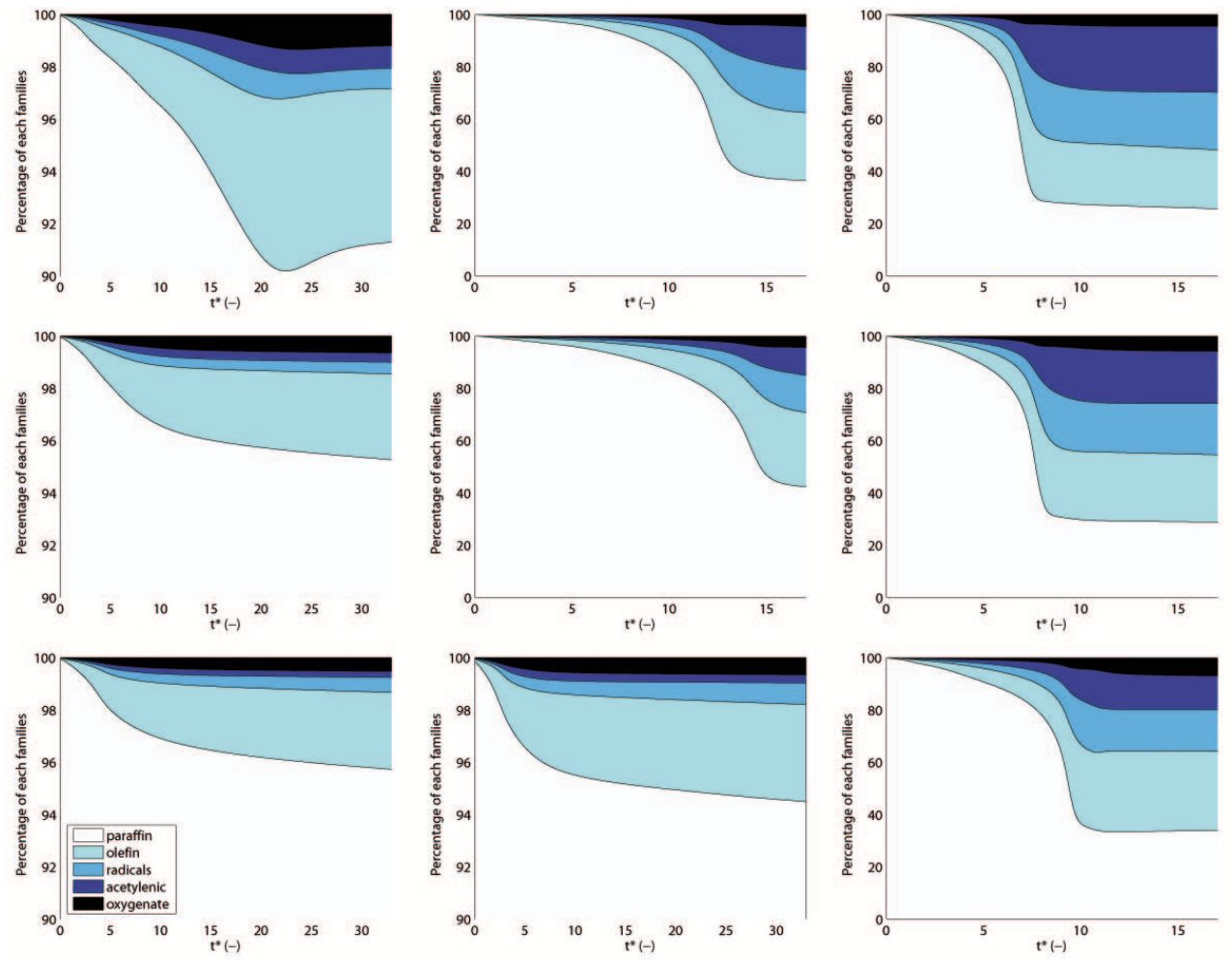

Figure 15: Time evolution of the percentage of each family (volume averaged values) when $T_{w}=300 \mathrm{~K}$ (first column), $T_{w}=400 \mathrm{~K}$ (second column), $T_{w}=500 \mathrm{~K}$ (third column) and $y^{*}=5$ (first line), $y^{*}=4$ (second line) and $y^{*}=3$ (third line) 


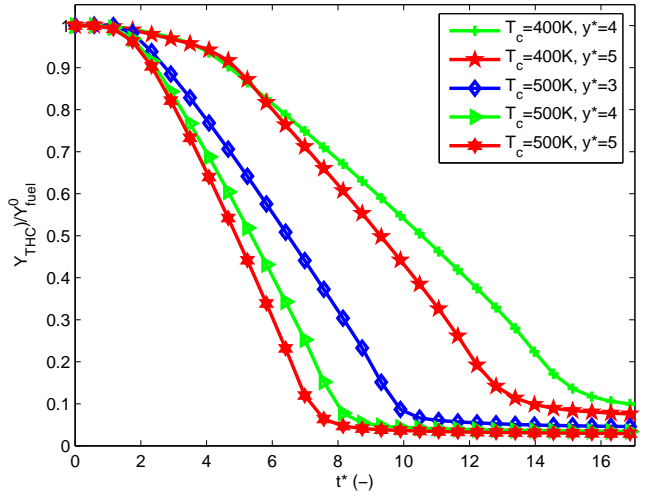

(a) - Propagating flame - case A

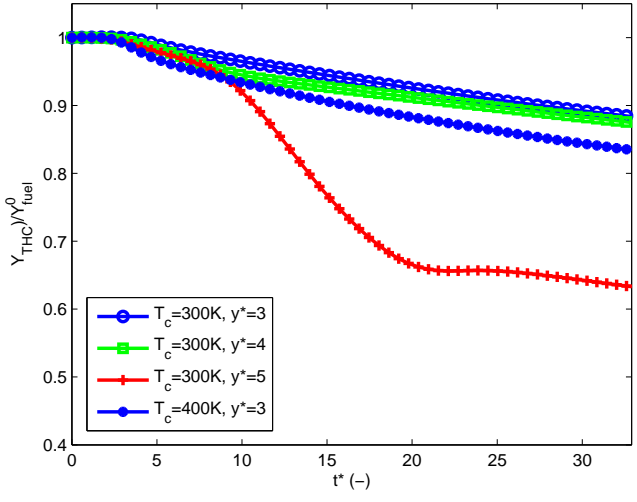

(b) - Still flame - case B

Figure 16: Time evolution of total HC along the symetry axis. 


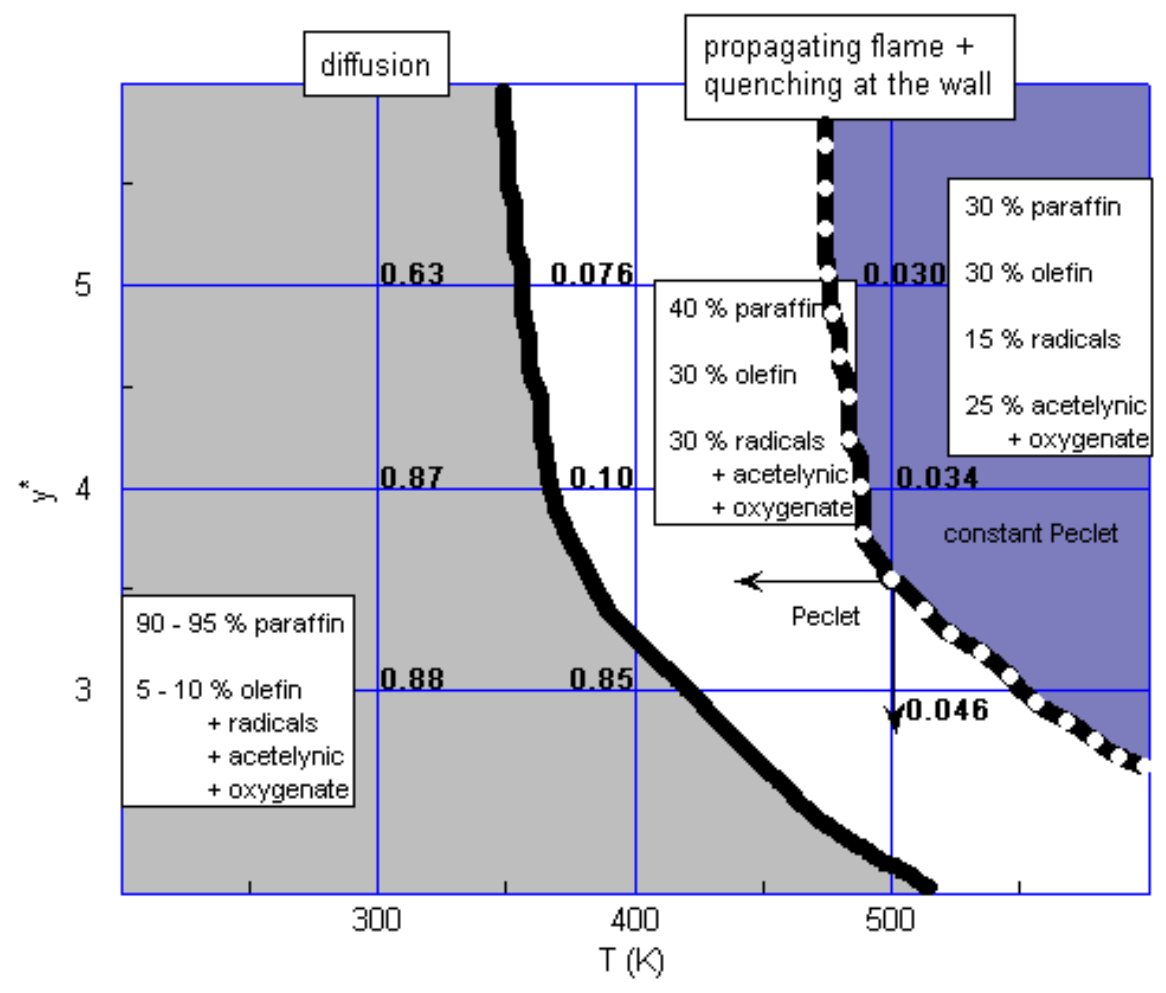

Figure 17: Diagram of the combustion modes in crevice with main HC families (frontier lines have been approximatively plotted). Total HC mass fraction normalized by initial fuel mass fraction are indicated at the grid nodes. 


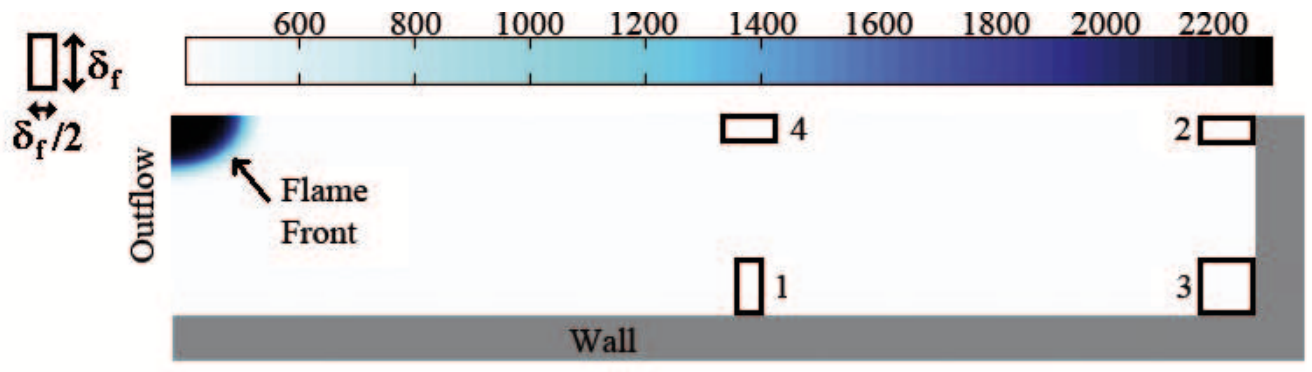

Figure 18: Positions and size of the four analysis surfaces. 

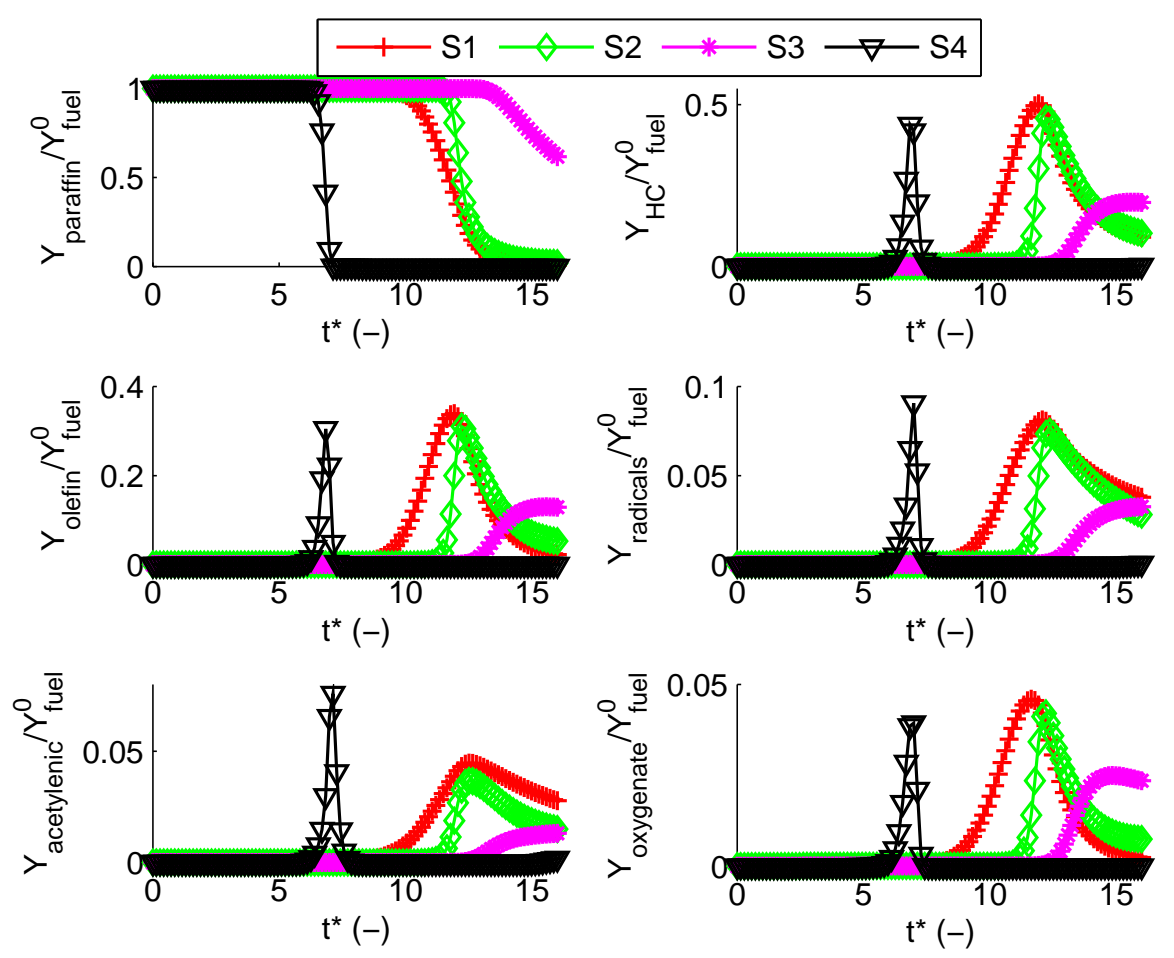

Figure 19: Unburnt HC time evolution in the various analysis surfaces of the domain. 